\title{
Experimental Research on Vibration Fatigue of CFRP and Its Influence Factors Based on Vibration Testing
}

\author{
Zhengwei Fan, Yu Jiang, Shufeng Zhang, and Xun Chen \\ Science and Technology on Integrated Logistics Support Laboratory, College of Mechatronic Engineering and Automation, \\ National University of Defense Technology, Changsha, Hunan 410073, China
}

Correspondence should be addressed to Yu Jiang; jiangyu@nudt.edu.cn

Received 15 March 2017; Revised 8 July 2017; Accepted 12 July 2017; Published 14 August 2017

Academic Editor: Toshiaki Natsuki

Copyright (C) 2017 Zhengwei Fan et al. This is an open access article distributed under the Creative Commons Attribution License, which permits unrestricted use, distribution, and reproduction in any medium, provided the original work is properly cited.

\begin{abstract}
A new research method based on vibration testing for the vibration fatigue of FRP was proposed in this paper. Through the testing on a closed-loop controlled vibration fatigue test system, the vibration fatigue phenomenon of typical carbon-fiber-reinforced plastic (CFRP) cantilevered laminate specimens was carefully studied. Moreover, a method based on the frequency response function was proposed to monitor the fatigue damage accumulation of specimens. On the basis of that, the influence factors that affect the vibration fatigue life of CFRP were experimentally studied. The influence of amplitude probability distribution of the vibration load spectrum on the fatigue life was deeply explored. Compared with Gaussian random vibration, the non-Gaussian random load has a significant impact on the vibration fatigue life of CFRP. The experimental results also showed that the magnitude of power spectral density (PSD) has a significant effect on the vibration fatigue life of specimens. For Gaussian vibration load, the frequency bandwidth almost has no effects on the vibration fatigue life of CFRP. However, for non-Gaussian vibration load, it has a great impact on the fatigue life. When PSD magnitude and frequency bandwidth are constant, the root mean square (RMS) is proportional to the vibration fatigue life of composites.
\end{abstract}

\section{Introduction}

Fiber-reinforced plastic (FRP) has been one of the most widely used composite materials in aerospace, ships, and vehicles, due to its design flexibility and excellent properties which are unmatched by metal materials. For decades, the amount of FRP used in a variety of facilities has been significantly increased. In some equipment, it even accounts for more than $50 \%$ of its total weight, such as the US new UAV $\mathrm{X} 47 \mathrm{~b}$, which is almost in all composite aircraft. With the large amount of fiber-reinforced composite materials used in various types of equipment, the reliability of composite structures in the service process becomes extremely important.

Equipment using FRP always suffers extreme and complex loads during its whole life, and those loads are definitely stochastic. As a result of that, the fatigue of composites is becoming inevitable and may cause catastrophic results. The use of composite materials on the key components of the engineering structure, such as aircraft wings and helicopter rotors, makes fatigue problems more critical. One of the most common fatigue phenomena is vibration fatigue. The FRP has fatigue resistance that is superior to that of a metal material and may be reliably serviced for a long time even after fatigue damage appears. In the early days when people began to use fiber-reinforced composites, they were considered to be free from fatigue due to the conservative safe life design of structure. However, with the rapid development of various types of aircraft, ships, and vehicles, the equipment system became more and more complicated, and its service environment and environmental load became more and more extreme. On the other hand, in the aerospace industry, engineering structures are often designed to pursue lighter quality but to carry more severe loads. As a result, the fatigue problem of composite materials gradually becomes unavoidable, and the fatigue problem of composite structures under realistic complex random loads is even more important [1].

There has been an extremely important and unavoidable question: how do we evaluate the fatigue life of the FRP structure and improve its durability, as well as the life 
determination and extension of serving facilities? Due to the anisotropy and inhomogeneity of the composites, the fatigue failure mechanism is completely different from that of the metal materials. It is a definitely difficult task to evaluate and predict the fatigue life of composite structures from a theoretical point of view.

For decades, the academic community has done a lot of research on the fatigue of composite materials. However, those studies were almost all carried out based on the fatigue tests under constant amplitude fatigue load. There are several common fatigue life evaluation methods of FRP, such as the experimental method based on S-N curve $[1,2]$, residual strength degradation model $[3,4]$, residual stiffness degradation model [5], energy dissipation model [6, 7], fatigue modulus model [8], and numerical analysis [9-12]. These models or methods have distinct advantages and disadvantages. Under certain conditions, the fatigue life of FRP can be evaluated and predicted through them, but there are some problems with large error and poor applicability.

For a long time, research on FRP fatigue has focused on a simple fatigue phenomenon under constant amplitude load, such as Tension-Tension (T-T), Tension-Compression (T-C), and Compression-Compression (C-C). However, the fatigue life under the uniaxial load during laboratory experiments is much different from that under realistic and irregular service load $[13,14]$. The load in the actual service for all kinds of engineering structures is not the constant amplitude load commonly used in the conventional fatigue test, but the random load with complex amplitude. The probability distribution of these loads often shows non-Gaussian and nonstationary characteristics. In the literature, it is shown that the composite structure will accelerate the crack propagation under the complex random load, which makes the conventional method under constant stress load obtain a result with a large error, which seriously affects the reliability of structural life evaluation [15].

Currently, there is very little literature on the fatigue life of composite structures under random and complex load. Fawaz and Ellyin explored the fatigue failure model of fiberreinforced materials under general load conditions from a theoretical point of view, taking into account factors such as multiaxial stress, stress ratio, fiber orientation, and load direction [16]. Van Paepegem and Degrieck used the numerical simulation to study the effect of loading sequence and block loading on the fatigue of fiber-reinforced composites [17]. Philippidis and Vassilopoulos studied the fatigue properties of glass fiber-reinforced plastic (GFRP) by using the load spectrum WISPERX, which is often used in the study of wind turbine blades, as well as the actual load spectrum derived from the working environment of aircraft rotors [18]. Vassilopoulos et al. studied the fatigue life simulation method of GFRP under irregular load and designed special numerical calculation software CCfatigue $[14,19]$. The works mentioned above are useful explorations of the fatigue life of composite structures under variable stress. However, there are still some shortcomings such as simplified load and poor applicability. Also, they do not take into account the vibration fatigue of composite structures under realistic random vibration loads.
Engineering structures under complex random vibration loads will suffer from vibration fatigue problems. So far, there have been many researches on the vibration fatigue of metal material structures. Eldoğan and Cigeroglu and Pothula et al. used a variety of fatigue theories to study the vibration fatigue life of metal cantilever beams $[20,21]$. Jiang et al. studied the accelerated model of vibration fatigue life of notched aluminum cantilever beam by accelerated testing in a typical closed-loop controlled system [22]. Aykan and Çelik analyzed the vibration fatigue life of aeronautical structures under multiaxial loads [23]. Unfortunately, as far as the authors know, the research on vibration fatigue of FRP structures caused by realistic vibration loads has not been deeply developed.

It is also important to note that it has been pointed out that the composite material is not sensitive to the notch under alternating loads in the literature [24]. The view is that the notch root of the composite material will form a damaged area to reduce the stress concentration, and the damage zone will expand during the fatigue process and mitigate the root stress concentration. This means that the risk point of the composite structure may not be the first place in fatigue damage, but in engineering practice the structure of the risk point is often the first to be concerned as the most likely area of damage. The sensitivity of the fatigue damage of composite structures to the notch under realistic random vibration loads needs further study.

The random vibration load is usually described by the power spectral density (PSD), but only one PSD parameter does not describe all types of random vibrations as the probability density distribution of the random vibrations may be completely different under the same PSD and RMS values [22], as shown in Figure 1.

For Gaussian random vibrations, the higher-order statistical moments greater than the second order are all zero, so the PSD can completely describe the Gaussian random vibration. However, for non-Gaussian random vibrations, the higher-order statistical moments ( $>2$ nd) are not constant zero, so both kurtosis and skewness are required. For random vibration $X$, its kurtosis is defined in

$$
K=\frac{E[X-E(X)]^{4}}{\left\{E[X-E(X)]^{2}\right\}^{2}} .
$$

The skewness is defined in

$$
S=\frac{E[X-E(X)]^{3}}{\left\{E[X-E(X)]^{2}\right\}^{3 / 2}} .
$$

For Gaussian random vibrations, $K$ is constantly equal to 3 and $S$ is constantly equal to 0 . As shown in Figure 1, when $K<3, X$ is a sub-Gaussian random vibration; when $K>3, X$ is a super-Gaussian random vibration. Both sub-Gaussian and super-Gaussian are collectively referred to as non-Gaussian. The skewness is used to measure the symmetry of the statistical data. Since the random vibration signal in engineering or that simulated in the laboratory is usually symmetrical, which means $S$ is 0 , this parameter is not studied in this paper. 


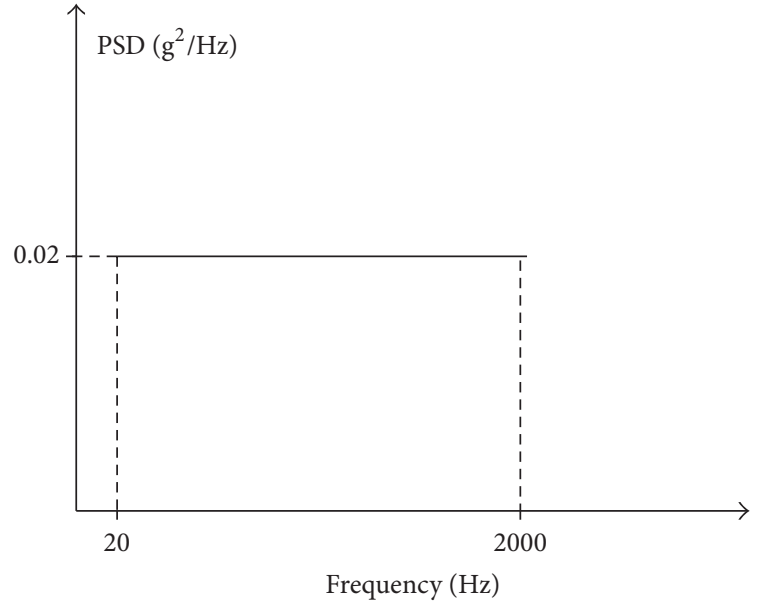

(a) Power spectral density

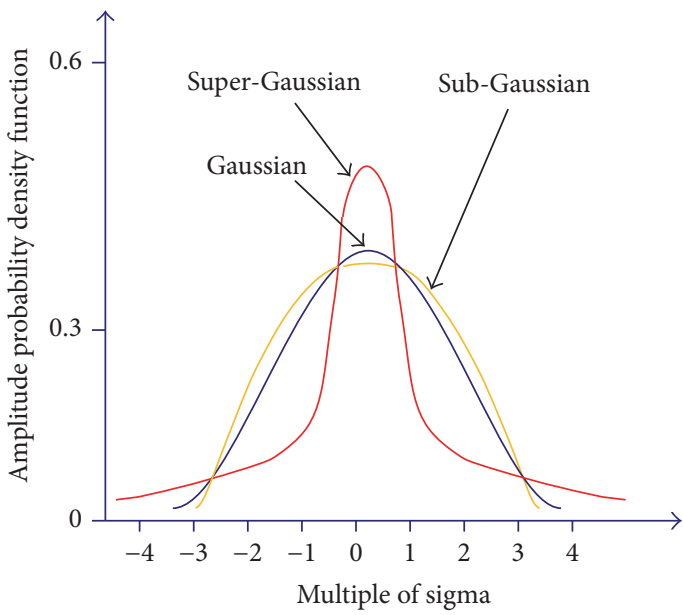

(b) Amplitude probability density function

FIGURE 1: The amplitude probability density function with the same PSD.

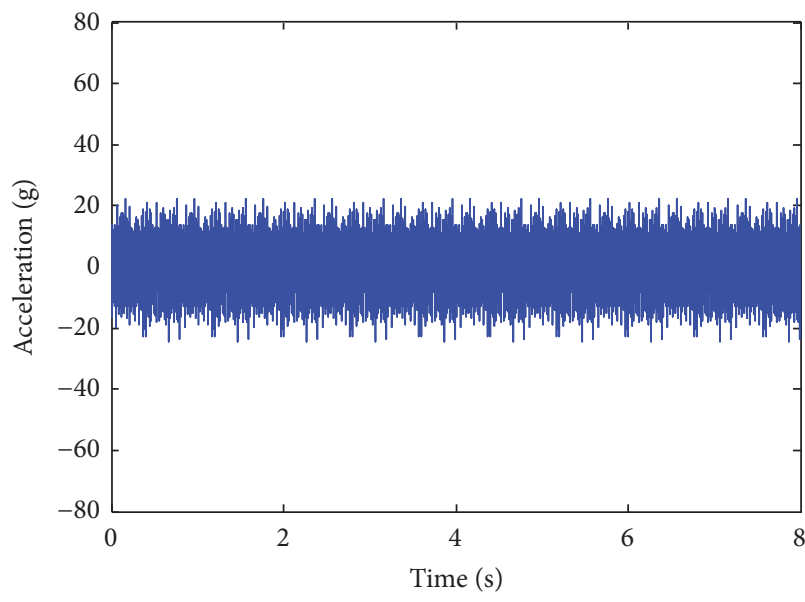

(a) Gaussian random vibration signal

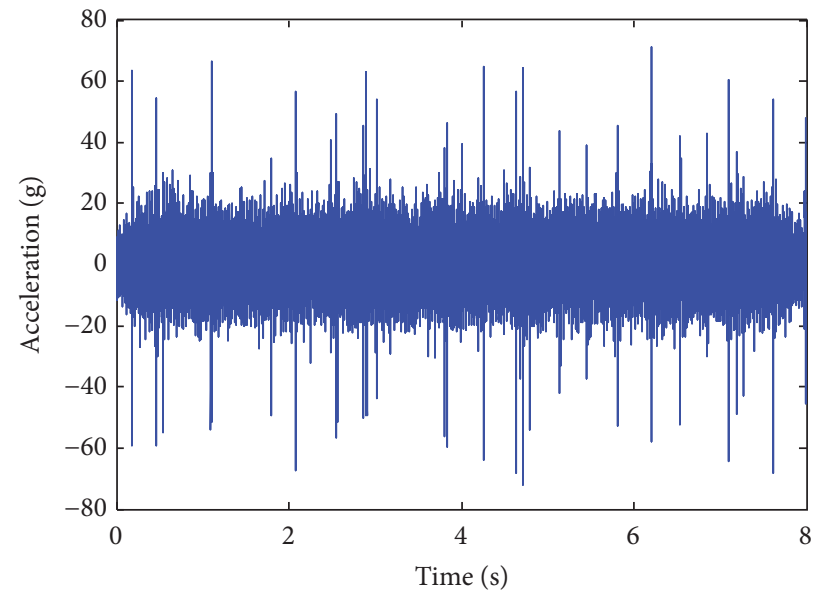

(b) Super-Gaussian random vibration signal

FIgURE 2: The difference between Gaussian and super-Gaussian random vibration signals.

The conventional research of vibration fatigue for metal structures is usually based on the assumption that the probability distribution of the stochastic vibration load is Gaussian. On the basis of this assumption, a series of signal processing approaches (e.g., cycle counting) were carried out to obtain the structural fatigue life. However, according to the actual investigation by our research team, the probability distribution of realistic vibration load applied on the facilities during their whole life is often subject to non-Gaussian distribution. With the hypothesis of Gaussian distribution, the predictive vibration fatigue life of equipment is longer than the realistic fatigue life, which is extremely unfavorable for fatigue life prediction and durability evaluation of composite structures [22]. On the other hand, the super-Gaussian random vibration load always contains more impact characteristics (Figure 2) than the Gaussian random load, which has a more significant influence on the damage emergence, propagation, and accumulation of FRP structures
[25]. Therefore, it is of great practical significance to study the vibration fatigue properties of composite structures under super-Gaussian random vibration.

The study on vibration fatigue of FRP under complex vibration load spectra was carried out based on vibration testing in this paper. A series of CFRP (carbon-fiberreinforced plastic) cantilevered laminate specimens with holes or notches were intended to be tested by random vibration testing in a developed closed-loop controlled vibration fatigue test system. Through the test, the obvious vibration fatigue phenomena can be observed at the risk point of the specimen, which is a predesigned hole or notch and is common in composite material structures. This vibration fatigue phenomenon is much different from conventional theory, which states that the composite is not sensible to risk points. On the basis of that, factors influencing the vibration fatigue life of specimens were explored through the fatigue test of several groups. In addition, the impact 


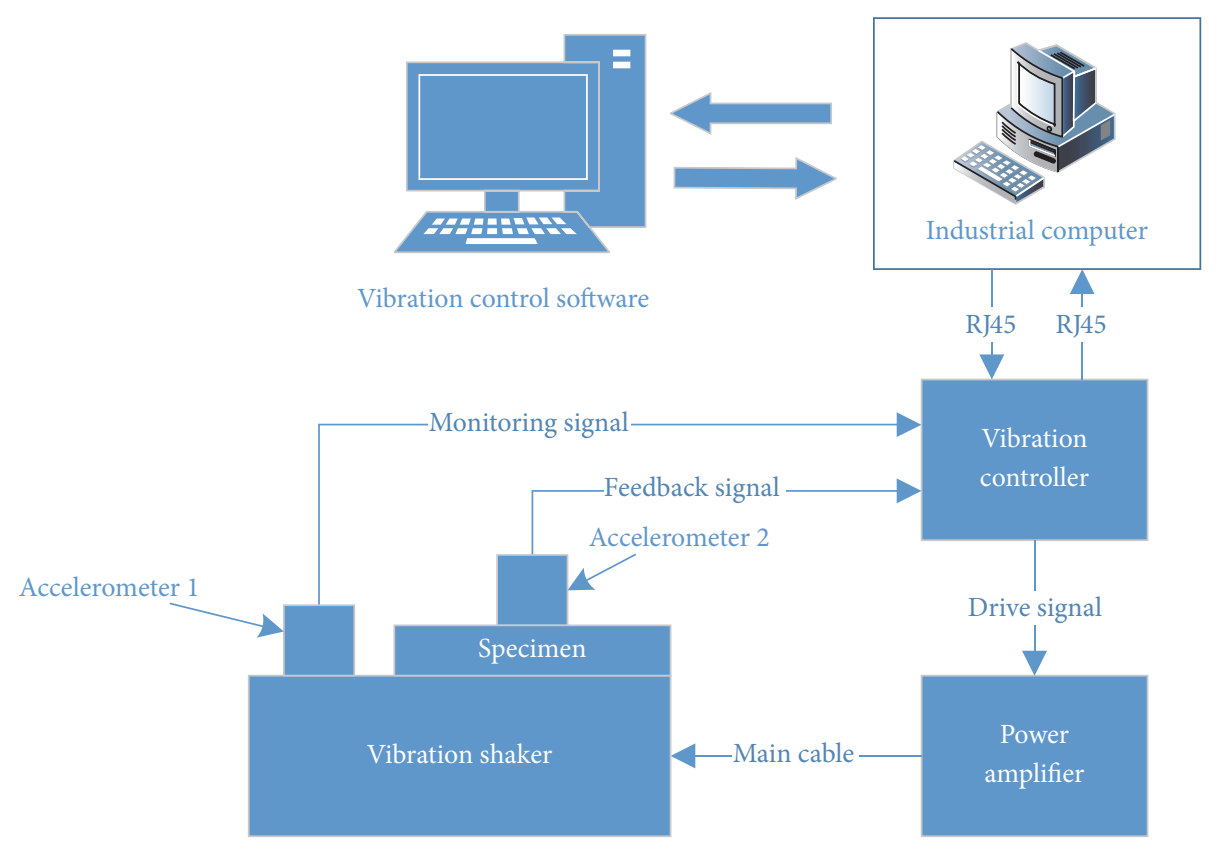

FIGURE 3: The schematic diagram of the vibration fatigue test system.

of amplitude probability distribution of the vibration load spectra on the fatigue life was also deeply studied. The study also makes a contribution to the establishment of the accelerated degradation test model and vibration fatigue life prediction.

Therefore, the objectives of this paper are as follows: (1) develop a vibration fatigue test system for composite materials; (2) verify the vibration fatigue phenomenon of composites and study the sensitivity of vibration fatigue damage to the risk points of structure; (3) explore the load factors which affect vibration fatigue life of composites.

\section{Test Setup}

2.1. The Closed-Loop Controlled Vibration Fatigue Test System. The test setup is a typical closed-loop controlled vibration fatigue test system, which consists of an industrial computer (vibration control software), vibration controller, power amplifier, shaker, and sensors. The control schematic diagram is shown in Figure 3, and the actual test equipment is shown in Figure 4.

The industrial computer is the carrier of the vibration control software and also the control core of the test system. The function of the industrial computer is to set the excitation signal parameters and test plan, real-time signal processing, and real-time closed-loop control for the shaker. The vibration controller is the medium for the output and receiving signal of the industrial computer. There is a network cable between the computer and the vibration controller for communication.

The vibration controller is the signal source and interface board of the system. The function of it is to generate the vibration control signal according to the instruction of the industrial computer, to receive the feedback and monitoring
TABLE 1: The technical parameters of STI D-150-2.

\begin{tabular}{lc}
\hline Item & Parameter \\
\hline Frequency range & $5-4500 \mathrm{~Hz}$ \\
Max. exciting force & $150 \mathrm{kgf}$ \\
Max. displacement & $25 \mathrm{~mm}(\mathrm{P}-\mathrm{P})$ \\
Max. velocity & $2 \mathrm{~m} / \mathrm{s}$ \\
Max. acceleration & $75 \mathrm{~g}$ \\
Max. load & $70 \mathrm{~kg}$ \\
\hline
\end{tabular}

signal, and to output the driving signal. The vibration controller used in the system is an RC-2000 vibration controller (with 8-channel input/output) from STI company. It can generate sine, random, and shock signals and is capable of controlling kurtosis, which can be used to carry out nonGaussian random vibration tests.

The main function of the power amplifier is to amplify the drive signal from the vibration controller into a large current drive signal and then transport it to the shaker. The function of the shaker is to generate a stimulus for the test piece mounted on the shaking table base according to the driving signal. The shaker used in this paper is an electromagnetic shaker, which is cooled by an air pump. The power amplifier and shaker chosen in the test are STI D-150-2 vibration test system. The technical parameters of the D-150-2 vibration test system are given in Table 1.

The sensor used in the test system is an accelerometer. The function of accelerometers is to collect monitoring and feedback vibration signal. Accelerometer 1 was mounted on the shaking table base and collected the signal to monitor the state of the excitation signal in real time to ensure that the actual vibration of the shaking table matches the preset excitation signal parameter. Accelerometer 2 was mounted 


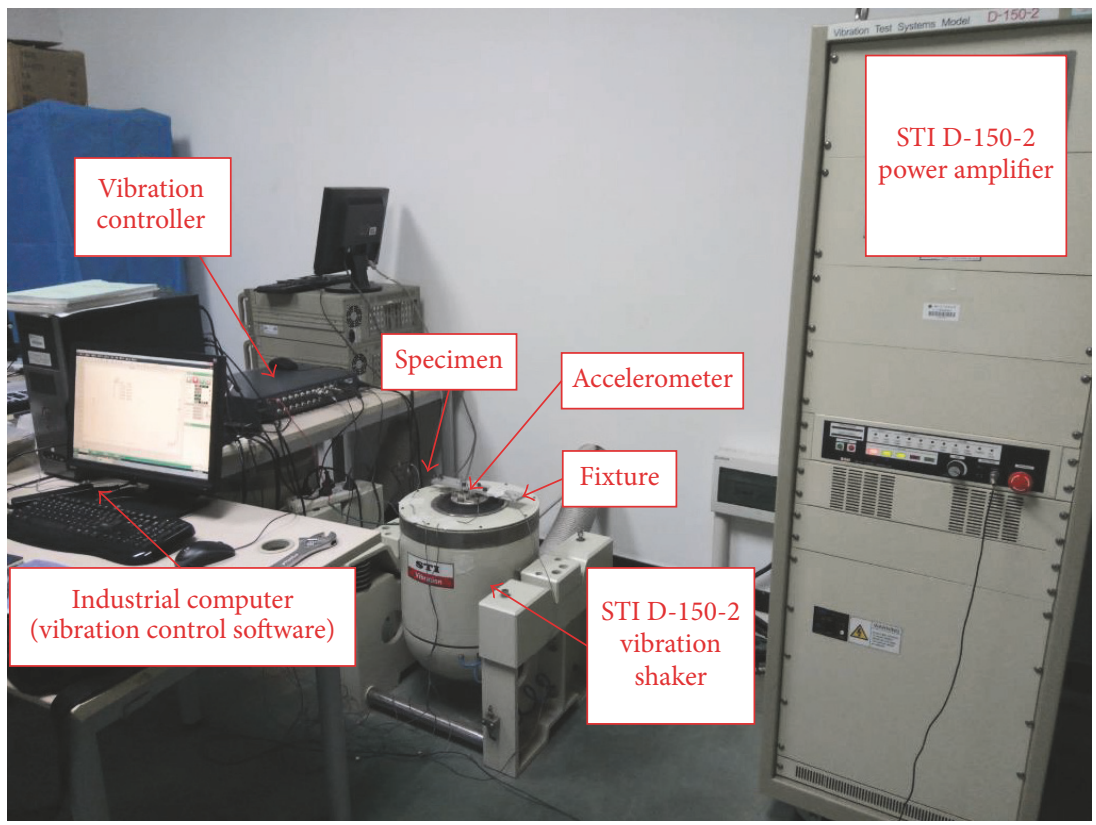

FIgURE 4: The actual vibration fatigue test system.

on the test piece and collected the feedback signal to obtain the vibration response of the test piece under the excitation signal. These two signals were sent to the computer through the vibration controller for further processing. The frequency response function of the test piece can be obtained based on signal processing. The accelerometers are B\&K $4508 \mathrm{~B}$ with $0.3-8 \mathrm{kHz}$ working frequency range and $\pm 71 \mathrm{~g}$ peak range.

\subsection{Online Monitoring of Fatigue Damage. For the metal} material, because of its isotropic nature and homogeneity of the material, fatigue damage can be described by the process of a dominant crack's derivative, propagation, and fracture. However, due to the completely different properties of FRP, the fatigue damage mechanism is very complex and cannot be described by a dominant crack. Currently, the commonly used composite material damage detection method is generally offline, such as radiographic testing, ultrasonic testing, infrared imaging, and acoustic emission. And it is difficult to monitor the fatigue damage of composite materials online. Besides, it is pointed out that the fatigue damage of the composite laminates is not sensitive to the risk point of the structure (notch, hole), and it is difficult to observe and judge the occurrence of fatigue damage with the human eye. The above reasons undoubtedly make it difficult to monitor the vibration fatigue damage of the composite in the test in real time, and it is also difficult to define the critical point of fatigue failure of the specimen, which makes it difficult to study the fatigue problem of the composites.

The relationship between the modal parameters and the fatigue damage of the structure was studied by Adams et al. [26-29], Kim et al. [30, 31], Salawu [32], Owolabi et al. [33], and Zou et al. [34] in the 1990s. The identification and detection of the material damage could be realized by monitoring the natural frequency and modal parameters of the structure. And according to the previous simulation and experimental research by authors [35], it was found that the damage of the composite laminates selected in this paper would decrease the natural frequency of the test piece. The natural frequency is decreased with the development of the fatigue damage. In the test system described in Section 2.1, the frequency response function can be obtained easily through the signals measured by sensors, so does the resonant frequency of specimens. Therefore, it is an effective and feasible means to monitor the derivative and propagation of fatigue damage by monitoring the resonant frequency's variation of the frequency response function (or transfer function) in the closed-loop controlled system. The real-time monitoring diagram is presented in Figure 5.

\section{Vibration Test}

3.1. Test Objectives. The main objective of this paper is divided into two aspects.

The first is to verify whether there is a vibration fatigue phenomenon in the composite structure under complex random vibration load and to study whether the fatigue damage of the composite structure under alternating load is sensitive to the risk point. By designing a typical composite cantilever test piece with different risk points, the vibration test was carried out under the same load conditions. In the course of the test, whether there is vibration fatigue damage at the location of risk point should be observed and its derivative law should be explored. In addition, the difference of the vibration fatigue phenomena of the two specimens with different ply sequences under the same load condition was compared by carrying out the vibration test with cross-ply and unidirectional ply specimens with the same risk point. 


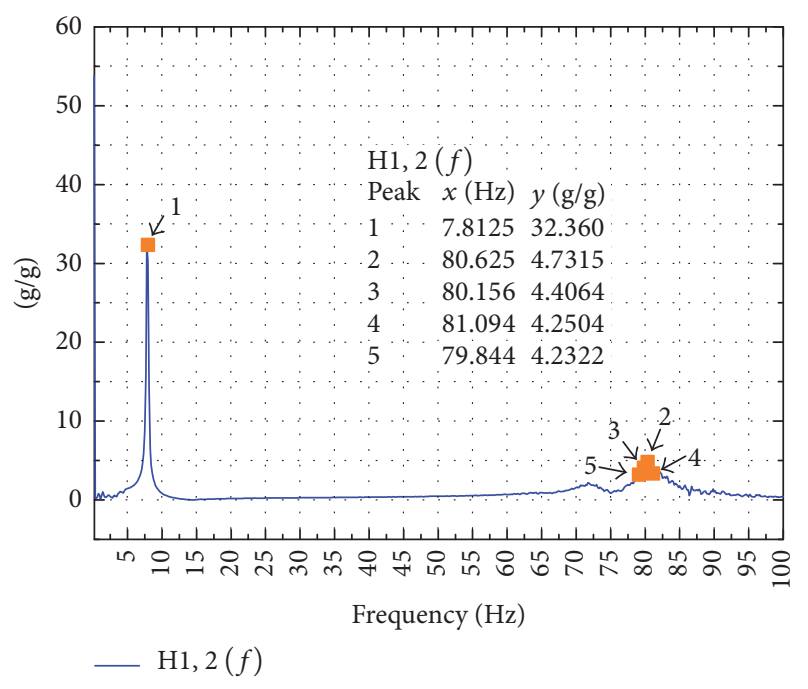

FIGURE 5: Frequency response function.

The second is to study the load influence factors on the vibration fatigue life of the composites on the basis of the verification of the vibration fatigue phenomenon in Test 1 . By changing the parameters of the load, the variable-controlling method is used to carry out the vibration test of the same specimen to explore the influence of the different parameters of the random vibration load on the vibration fatigue damage of the composite material, which will lay the foundation for the future study.

The load in the vibration fatigue test is random vibration load, which is completely different from those of the conventional composite fatigue test. As shown in Figure 6, the load commonly used in the conventional fatigue test is the constant amplitude load, which can be described by the period $(T)$, frequency $(f r)$, amplitude $\left(\sigma_{a}\right)$, mean cyclic stress $\left(\sigma_{\text {mean }}\right)$, stress range $(\Delta \sigma)$, maximum cyclic stress $\left(\sigma_{\max }\right)$, minimum cyclic stress $\left(\sigma_{\min }\right)$, stress ratio $(R)$, and some other parameters. According to the different stress ratios, the constant amplitude load can be divided into Tension-Tension (T-T), Tension-Compression (T-C), and Compression-Compression (C-C) load (see Figure 6(b)). However, for random vibration, the amplitude, frequency, and mean stress of the load are continuously changed over time (as shown in Figure 7(b)), so the random vibration load cannot be described by the above parameters. Figure $7(a)$ is a flat PSD spectrum of a typical random vibration signal. The random vibration load can be described by the parameters in Figure $7(\mathrm{a})$, such as frequency bandwidth, PSD magnitude, minimum frequency, maximum frequency, RMS (root mean square) value, kurtosis, and skewness mentioned above. Since the skewness of the random vibration load in engineering is always small (approximately equal to 0 ), the vibration load can be regarded as symmetrical. As a result, the skewness is not studied in this paper. And the vibration test mainly explored the effects of frequency bandwidth, PSD magnitude, kurtosis, and RMS value on vibration fatigue life of composites.
TABLE 2: Mechanical property parameters.

\begin{tabular}{lc}
\hline Item & Parameter \\
\hline$E_{1}$ & $136.00 \mathrm{GPa}$ \\
$E_{2}=E_{3}$ & $9.80 \mathrm{GPa}$ \\
$G_{12}=G_{13}$ & $4.70 \mathrm{GPa}$ \\
$G_{23}$ & $5.20 \mathrm{GPa}$ \\
$\mu_{12}=\mu_{13}$ & 0.280 \\
$\mu_{13}$ & 0.150 \\
$\rho$ & $1540 \mathrm{~kg} / \mathrm{m}^{3}$ \\
${ }^{*} E$ is Young's modulus; $G$ is shear modulus; $\mu$ is Poisson's ratio; $\rho$ is density.
\end{tabular}

3.2. Test Materials. T300 carbon fiber-reinforced epoxy resin composite laminates, which are widely used in the aerospace, vehicle, and ship industry, were chosen to carry out the tests in this paper. The mechanical property parameters of materials are presented in Table 2 .

The eight-layer laminates with a single layer thickness of $0.125 \mathrm{~mm}$ and a total thickness of $1 \mathrm{~mm}$ were selected. In addition, two kinds of laminates with different ply stacking sequences $\left(\left[90^{\circ} / 0^{\circ} / 90^{\circ} / 0^{\circ}\right]_{s}\right.$ and unidirectional) were used to explore the influence of ply sequences on the vibration fatigue of laminates.

3.3. Specimens. The specimen dimensions are shown in Figure 8 . The specimen is a typical cantilever laminate with three different kinds of risk points. The specimens were $180 \mathrm{~mm}$ long and had a width of $16 \mathrm{~mm}$. Their nominal thickness was $1 \mathrm{~mm}$. The purpose of the design of the cantilever laminate with three different risk points is to verify whether the composite structure has vibration fatigue under the random vibration load and to study the sensitivity of the vibration fatigue damage to the risk point (e.g., through-hole, notch) under alternating load. Specimen 1 was a cantilevered beam with a through-hole (the diameter is $10 \mathrm{~mm}$ ), while Specimens 2 and 3 were beams with notch and double through-holes (the diameter is $4 \mathrm{~mm}$ ), respectively. These three forms of risk points of CFRP are very common in engineering practice and so have a good representation. The through-hole at the left end of the specimen was a fixture hole. During the test, the specimen is fixed on the shaking table base through the bolted joint, and the left shaded part of the specimen is the clamping area. Another through-hole at the right end is the mounting hole for tip mass. The tip mass was an effective approach to accelerate the test process and compress the test cost. Several bolts and nuts were chosen as the tip mass because they can easily change the mass. The shaded part near the mounting hole of tip mass is the mounting area of the feedback signal accelerometer. The reason for installing the accelerometer next to the tip mass is that the mass of the accelerometer can be considered to be included in the tip mass when the two are close together, so as to avoid the change of vibration characteristics of the specimen. The actual specimens are shown in Figure 9(a).

In order to study the vibration fatigue of specimens with different ply angles, two kinds of CFRP laminates with different ply sequences were selected. One is cross-ply and 


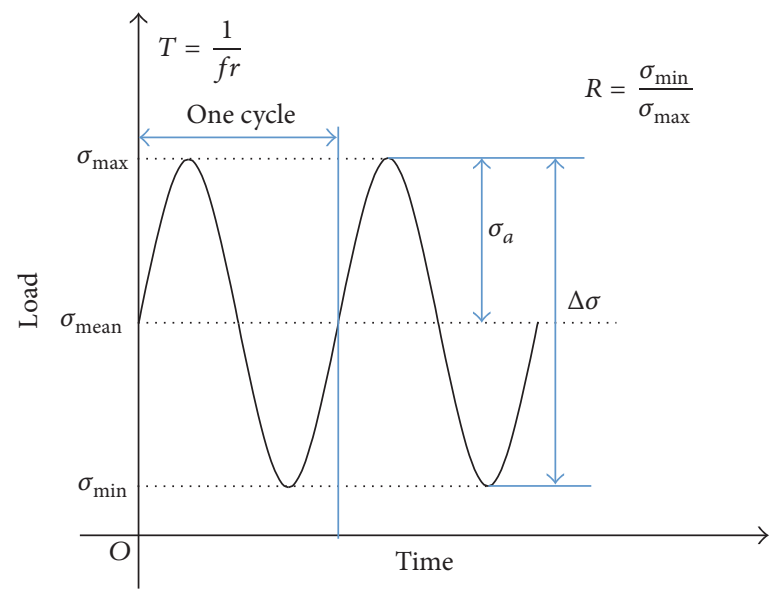

(a) The typical cycling load

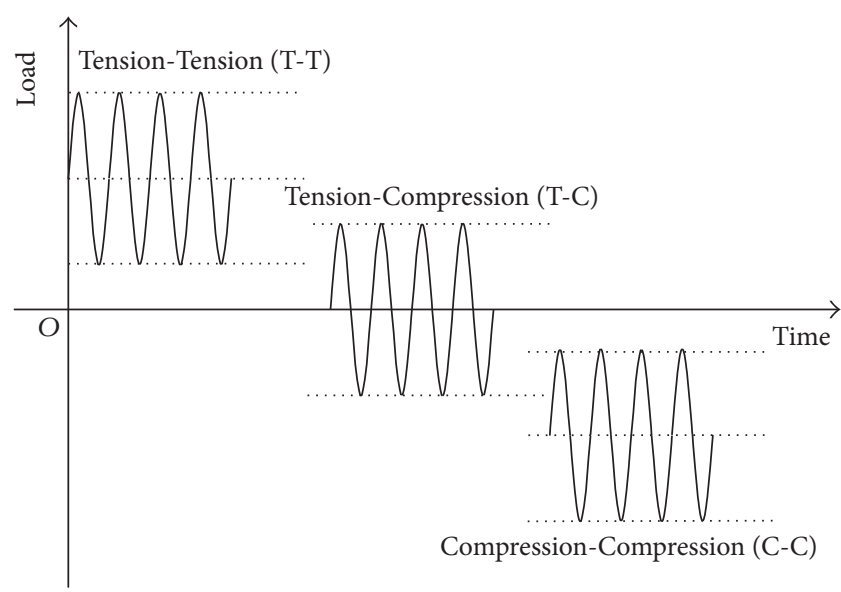

(b) The load with different stress ratio

Figure 6: The constant amplitude load of fatigue test for composite materials.

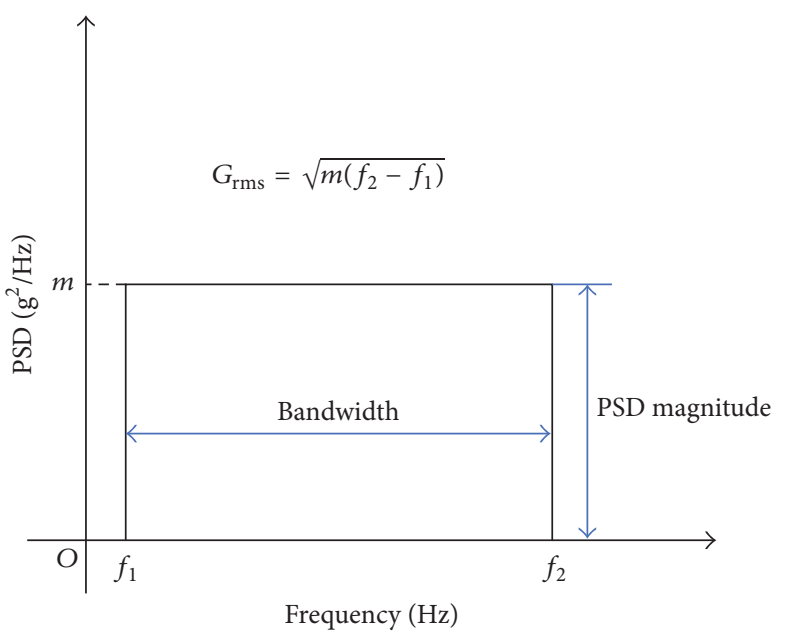

(a) The PSD of a random vibration load

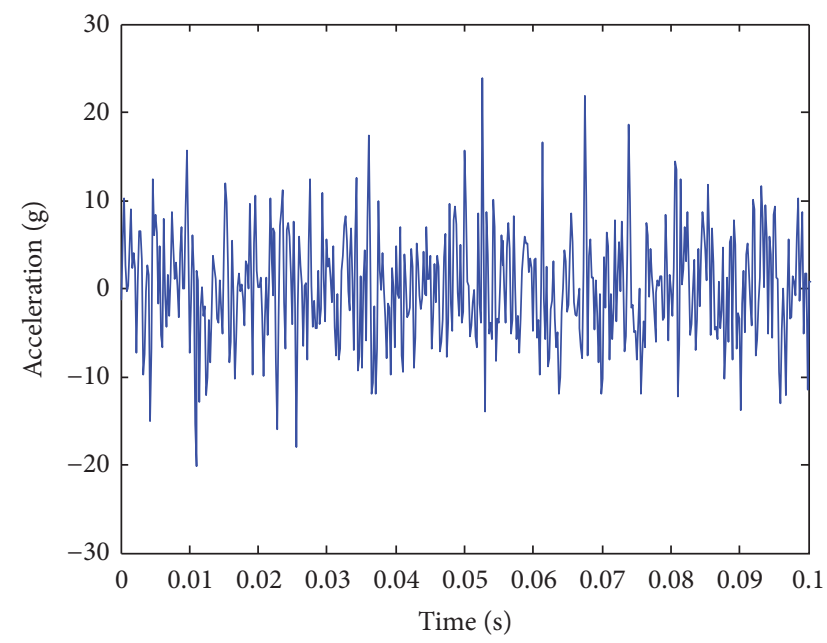

(b) The time domain signal of a random vibration load

FIgURE 7: The random vibration load of fatigue test for composite materials.

the other is unidirectional. The top view of the three kinds of specimens and the profile map of the two different materials are shown in Figures 9(b) and 9(c). During the test, two kinds of specimens with the same dimension but different ply angles were tested under the same load conditions, and then the test results were compared. The actual fixture of the specimen is shown in Figure 10, in which two specimens (Specimens 1 and 3) were mounted on the shaking table base.

3.4. Test Procedure. A complete vibration test procedure is as follows.

Step 1: Test Preparation. Clamp the specimen onto the shaking table base, install the accelerometers, connect the equipment, and check whether the equipment is running normally. Initialize the vibration control software and set the test parameters as required.
Step 2: Pretest. Pretest is required before the formal test to check whether the parameter settings are reasonable, to confirm the normal operation of the equipment, and to determine the quality of the tip mass. For the same structure, the fatigue resistance of the composite material is better than that of the metal material, which means that the vibration fatigue test of the composite material is longer than that of the general metal material. A very long test time will cause the test cost to increase and is not conducive to the research in the laboratory. If the vibration test can be accelerated without changing the vibration fatigue failure mechanism of the composite material, the test cycle and the test cost can be greatly shortened. Therefore, the tip mass was installed at the end of the specimen to speed up the test. The quality of the tip mass has a significant impact on the test time. In order to select a reasonable quality of it, a pretest is required before the formal test. If the tip mass is too heavy, the specimen would 


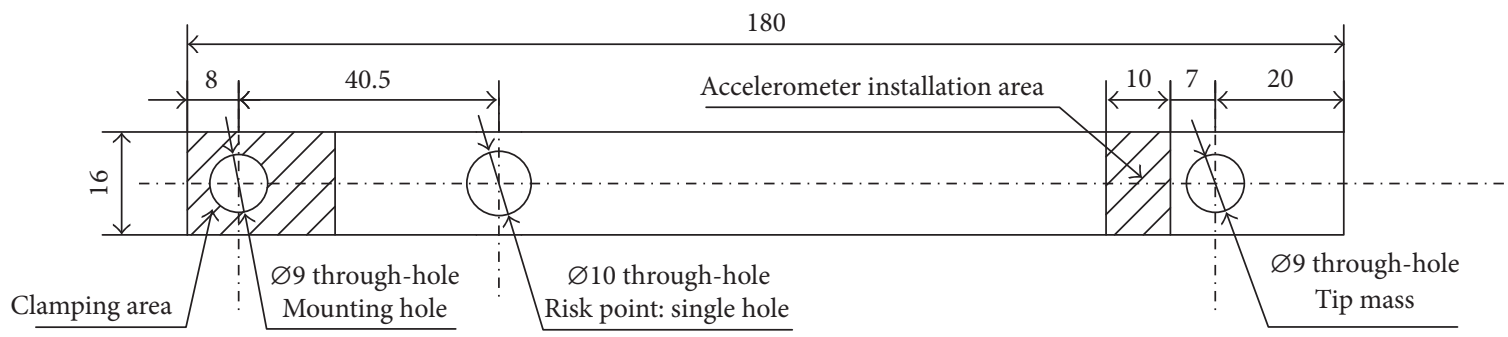

(a) Specimen 1

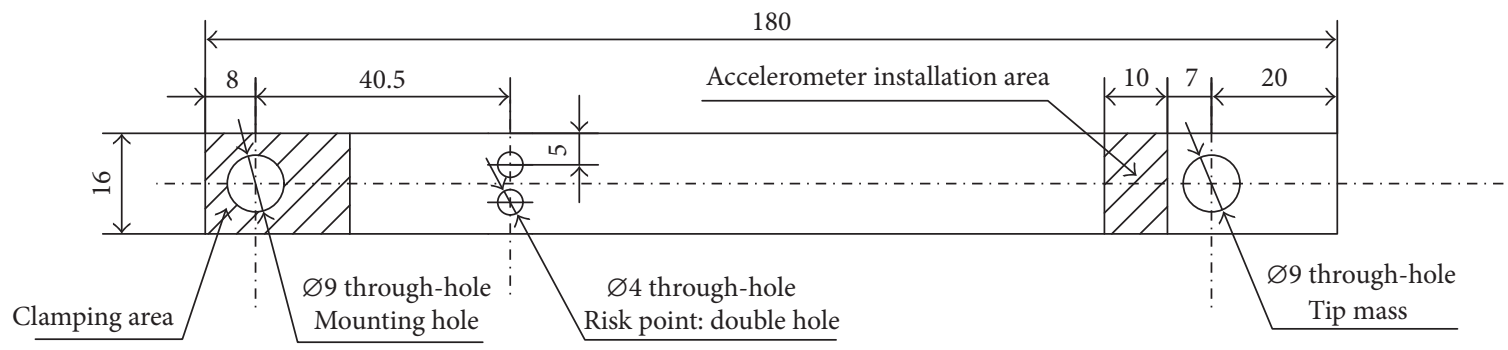

(b) Specimen 2

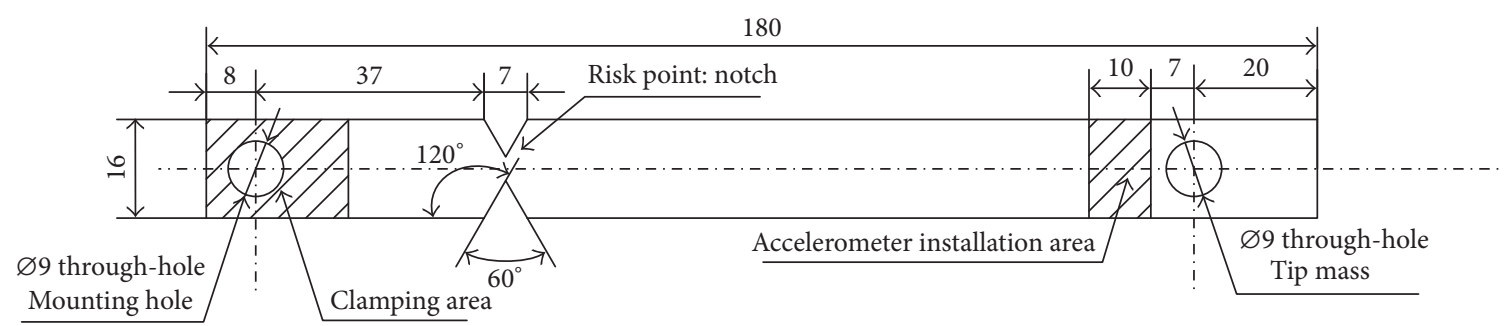

(c) Specimen 3

Figure 8: The specimen of vibration testing.

fail quickly, but this kind of failure may not be a fatigue failure. This means that a short test time could cause the test data to be unreliable. Pretest found that, in order not to change the fatigue failure mechanism of the specimen, the quality of the tip mass needs to ensure that the failure time of the specimen is more than $0.5 \mathrm{~h}$. Taking into account the test cycle and cost, according to the former tests, the reasonable tip mass should be $36.6 \mathrm{~g}$ for cross-ply specimens and $22 \mathrm{~g}$ for unidirectional specimens. When the test time reaches $3 \mathrm{~h}$, the resonant frequency of the frequency response function decreases by about 3-5\%, while the relevant literature [30] indicates that this can be considered as vibration fatigue failure. Therefore, the test time in this paper is controlled between $0.5 \mathrm{~h}$ and $3 \mathrm{~h}$, which is an ideal and reasonable test time.

Step 3: Sine Sweep Test. For the vibration fatigue test, the frequency bandwidth of the excitation signal must cover the natural frequency of the structure in order to make the structure resonate. In this paper, the frequency of the excitation signal is chosen to cover the first-order natural frequency of the structure. In order to obtain the natural frequency of the structure and select the bandwidth of the excitation signal reasonably, it is necessary to perform the sinusoidal sweep test before the formal test, that is, to input the sinusoidal excitation signal in order from low frequency to high frequency. Sine sweep test was implemented in a frequency range of $5-2000 \mathrm{~Hz}$. Sensor 1 measured the excitation signal in real time, and Sensor 2 measured the response signal in real time. These two signals were simultaneously transmitted to the computer for real-time signal processing to obtain the frequency response function. The overall natural frequencies were also obtained through the frequency response function. According to the test results, the first-order natural frequency of the specimen is about $8 \mathrm{~Hz}$.

Step 4: Fatigue Test. After the above steps, test conditions (load) were designed (see Section 3.5), and the formal vibration fatigue test was carried out. The test conditions and test plan were set in the vibration control software, and then vibration tests were carried out in accordance with the designed test conditions and continued until the test specimen failed. During the test, the fatigue damage of the specimen was monitored by the fatigue damage monitoring method described above, and the corresponding test data were recorded in real time.

Step 5: End the Test and Data Processing. Repeat Step 4 for all test conditions in Section 3.5. Due to the large dispersity of the composite [36-38], a number of specimens should be tested for each test condition to obtain a credible result. After 


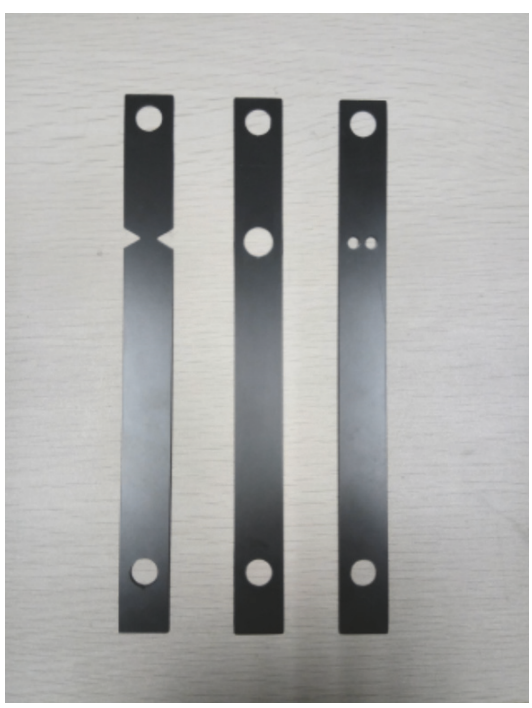

(a) Specimens

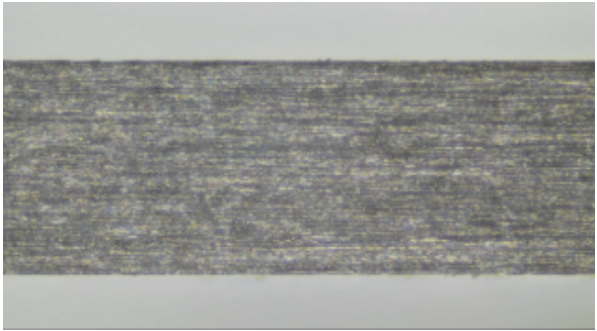

(b) Unidirectional

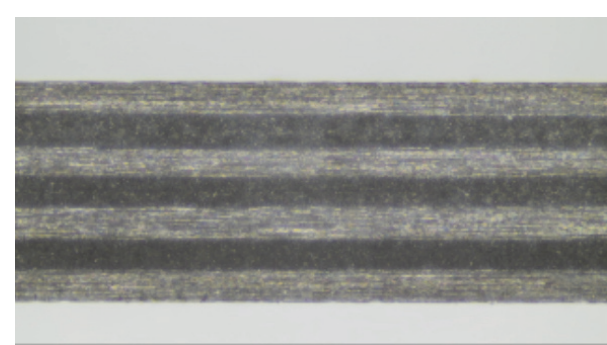

(c) Cross-ply

FIGURE 9: The top view and profile map of specimens.

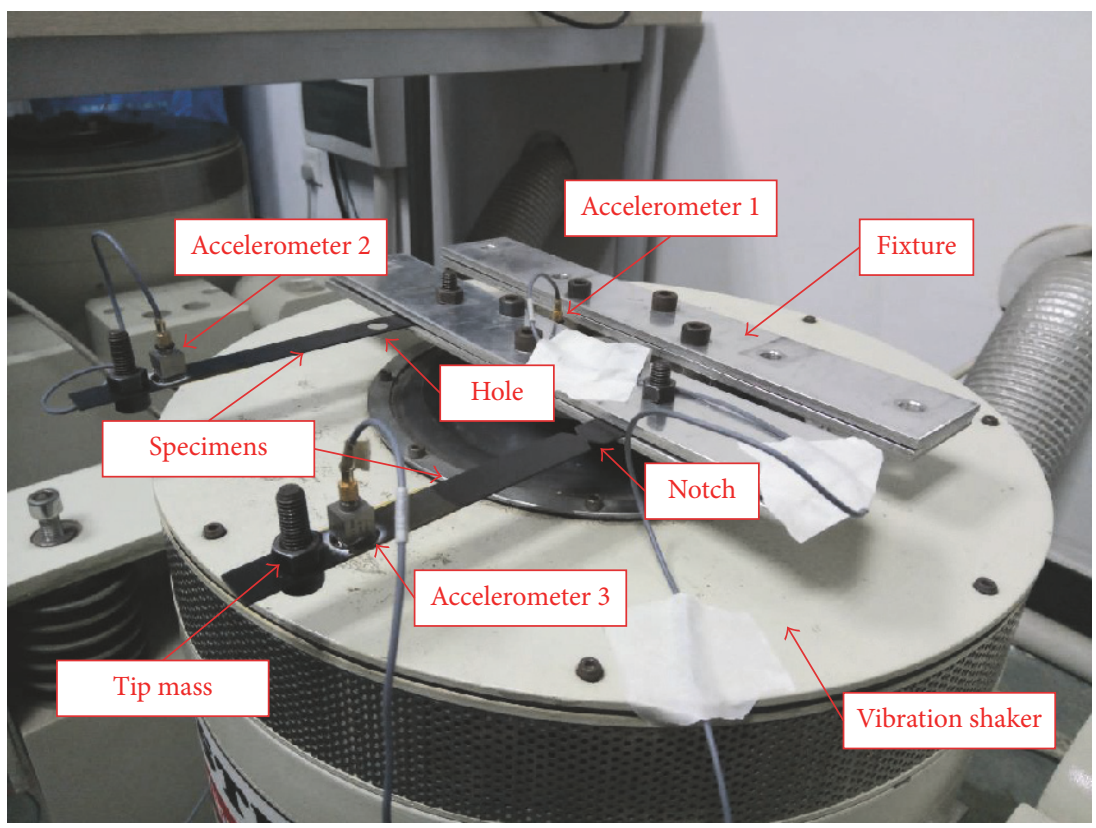

FIgURE 10: The fixtures of specimens, tip mass, and accelerometers. 
TABle 3: The test conditions of Test 1.

\begin{tabular}{lccccc}
\hline Specimen & Lower frequency $(\mathrm{Hz})$ & Upper frequency $(\mathrm{Hz})$ & PSD bandwidth $(\mathrm{Hz})$ & $\begin{array}{c}\text { Acceleration } \\
\text { PSD magnitude } \\
\left(\mathrm{g}^{2} / \mathrm{Hz}\right)\end{array}$ & $\begin{array}{c}G_{\text {rms }}(\mathrm{g}) \\
\text { Kurtosis }\end{array}$ \\
\hline Unidirectional & 5 & 100 & 95 & 0.01 & 0.974676 \\
Cross-ply & 5 & 100 & 95 & 0.01 & 0.974676 \\
\hline
\end{tabular}

TABle 4: The test conditions of Test 2.

\begin{tabular}{lcccccc}
\hline Item & Lower frequency $(\mathrm{Hz})$ & Upper frequency $(\mathrm{Hz})$ & PSD bandwidth $(\mathrm{Hz})$ & Acceleration PSD magnitude $\left(\mathrm{g}^{2} / \mathrm{Hz}\right)$ & $G_{\mathrm{rms}}(\mathrm{g})$ & $\mathrm{Kurtosis}$ \\
\hline A1 & 5 & 100 & 95 & 0.01 & 0.974676 \\
$\mathrm{~A} 2$ & 5 & 100 & 95 & 0.01 & 3 \\
$\mathrm{~A} 3$ & 5 & 100 & 95 & 0.01 & 0.974676 \\
B1 & 5 & 35 & 30 & 0.01 & 0.974676 \\
B2 & 5 & 65 & 60 & 0.01 & 7 \\
B3 (A1) & 5 & 100 & 95 & 0.01 & 0.54681 \\
C1 & 5 & 35 & 30 & 0.01 & 3 \\
C2 & 5 & 65 & 60 & 0.01 & 0.9744595 \\
C3 (A2) & 5 & 100 & 95 & 0.01 & 3 \\
D1 (B2) & 5 & 65 & 60 & 0.01 & 0.54681 \\
D2 & 5 & 65 & 60 & 0.015 & 5 \\
D3 & 5 & 65 & 60 & 0.02 & 0.9744595 \\
E1 (C2) & 5 & 65 & 60 & 0.01 & 5 \\
E2 & 5 & 65 & 60 & 0.015 & 0.774595 \\
E3 & 5 & 65 & 60 & 0.02 & 3 \\
\hline
\end{tabular}

the test, the recorded experimental data were compiled and processed, the cumulative rate of vibration fatigue damage was evaluated, and the factors affecting the vibration fatigue of the composites were analyzed.

3.5. Test Conditions (Vibration Load). According to the test objective in Section 3.1 and pretest results in Section 3.4, the test conditions of Test 1 and Test 2 are designed and shown in Tables 3 and 4, respectively.

In Test 1 , in order to verify the presence or absence of vibration fatigue of the composite laminates and to explore the sensitivity of vibration fatigue damage to risk points under random loads, Specimen 1 with the same geometrical dimensions but different layers (cross-ply and unidirectional) and cross-ply Specimen 2 and Specimen 3 were, respectively, tested on the shaker with the same test conditions.

The purpose of Test 2 is to explore the influence of PSD, RMS, frequency bandwidth, and kurtosis on the vibration fatigue life of composite materials. Cross-ply Specimen 1 was selected as the object to carry out the test. The test conditions are shown in Table 4.

The purpose of Group A is to investigate the influence of kurtosis on the vibration fatigue life of composite materials, while that of Group B is to explore the impact of Gaussian random vibration frequency bandwidth on fatigue life. Group $\mathrm{C}$ was designed to study the effect of super-Gaussian random vibration frequency bandwidth on the fatigue life of specimens. The purpose of Groups D and E was to investigate the effect of the Gaussian and non-Gaussian random vibration PSD on the vibration fatigue life, respectively. The RMS value of the random vibration load is affected by both bandwidth and PSD; it is not the main influence factor.

It can be seen from Table 4 that the test conditions of $\mathrm{A} 1$ and B3, A2 and C3, D1 and B2, and E1 and C2 are exactly the same, which can greatly compress the number of test samples and effectively reduce the test time.

The load in the test is a random vibration load with a flat PSD spectrum, which means the PSD spectrum of the load is flat. The real-time autopower spectral density of test condition A1 is shown in Figure 11.

\section{Test Results and Discussion}

4.1. The Vibration Fatigue Phenomenon of CFRP. According to the test conditions in Section 3.5, Test 1 was carried out using three kinds of cross-ply specimens (Specimens 1-3) and one kind of unidirectional specimen (Specimen 1). It was found that the specimens had an obvious vibration fatigue phenomenon under the random vibration load. As shown in Figure 12, different specimens in the test were all observed having macroscopic cracks in tangential positions along the notch or through-hole. Figure 12(a) shows three different specimens of Specimen 3. It can be clearly seen that the crack length increased with the increase in test time, which indicated that there was a vibration fatigue phenomenon emerging and fatigue damage accumulation at the risk point. Figure 13 shows a comparison of three different cross-ply specimens before and after the test. After the same test time, all the three specimens had tangential fatigue cracks of different lengths. This means that, under 


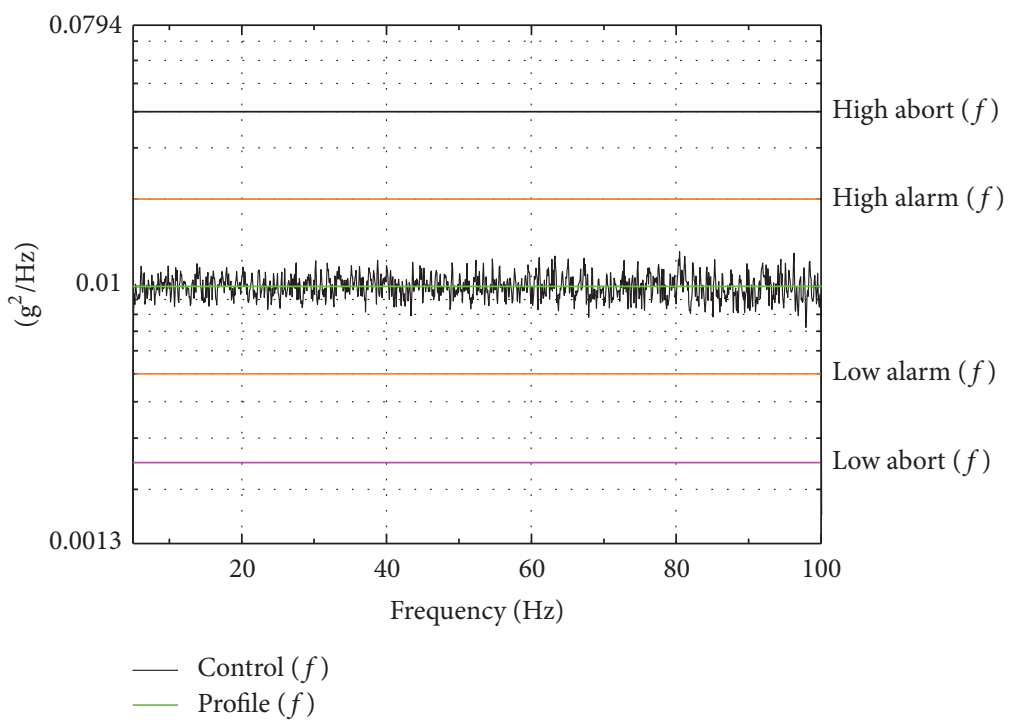

FIGURE 11: The autopower spectral density of vibration load.

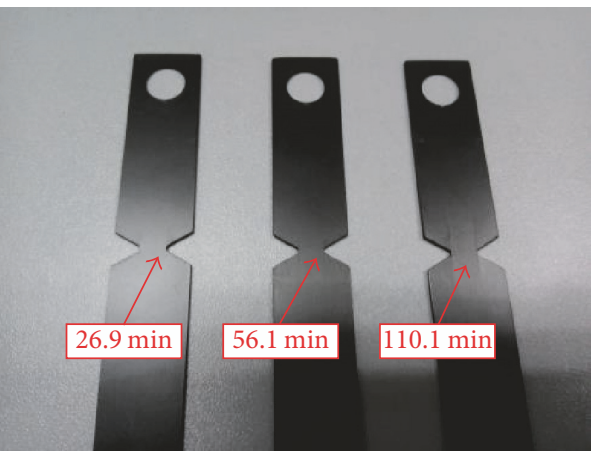

(a) Notched specimens

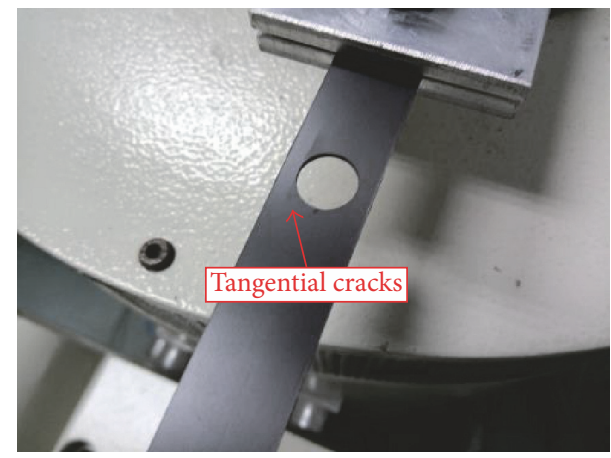

(b) Specimen with a hole

FIgURE 12: The vibration fatigue of specimens.

the random vibration load, the CFRP is sensitive to the risk points (notch or through-hole). There is a significant stress concentration phenomenon at the risk point. The stress concentration mitigation pointed out in the relevant literature is not evident. The damage generally first emerges in the risk point of the structure and the first crack emerges at the maximum stress position. As the load time increases, the crack gradually expands until it fails.

4.2. The Vibration Fatigue with Different Ply Sequences. As shown in Figure 14, the failure modes of the specimen with different ply sequences under the random vibration load were different. Figure 14(a) shows the cross-ply specimen, and Figure 14(b) shows the unidirectional specimen. The former specimen had tangential cracks along the hole and delamination damage at the end of the test, while the latter specimen exhibited tangential cracks and fracture eventually. The fracture surface was a slope and the fatigue life was much smaller than the former specimen. The finite element analysis (FEA) results of the specimen are given in Figure 15. From the figure, it can be seen that there is a large shear stress in the tangential direction of the hole. The transverse strength of the unidirectional specimen is only dependent on the strength of the matrix, which is much weaker than the fiber. Consequently, the unidirectional specimen would quickly fail compared with the cross-ply specimen under the same load condition.

4.3. Effects of Kurtosis on Vibration Fatigue of CFRP. Crossply Specimen 1 was selected to carry out Test 2 according to the test conditions in Section 3.5. All the specimens were tested with a duration of 3 hours, and some of the damaged test specimens are shown in Figure 16.

The test results of Group A are shown in Table 5. In order to show the decrease rate of resonant frequency of each test condition more intuitively, Table 5 shows the reduction of the resonant frequency after test and gives the last decrease time of the frequency. Figure 17 shows the trend of the resonant frequency of the test specimen under the three test conditions in Group A. As can be seen from Table 5 and Figure 17, the resonant frequency decreases gradually as the test time increases, but the decrease rate of $\mathrm{A} 3$ is the fastest, which 


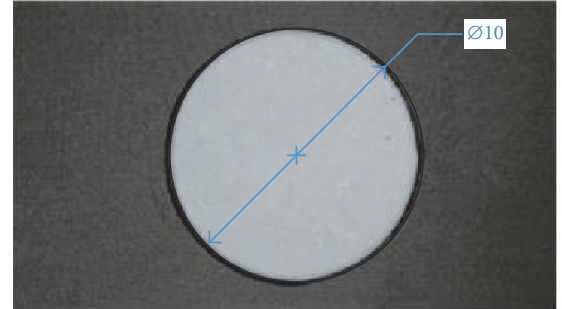

Before test

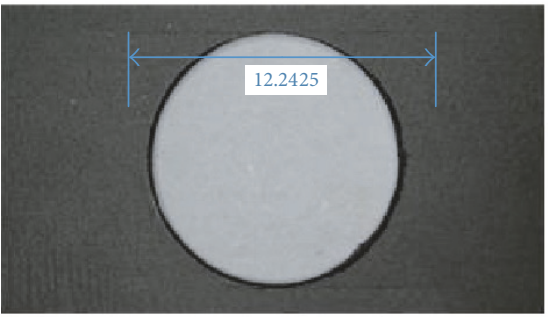

After test

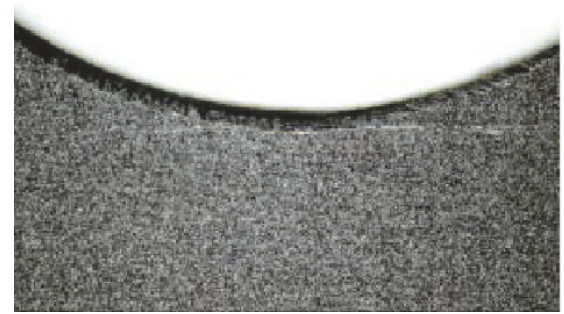

Enlarged view

Specimen 1

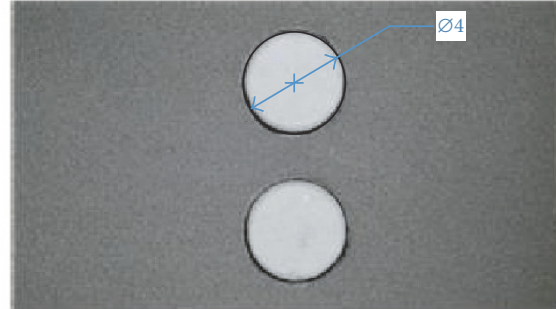

Before test

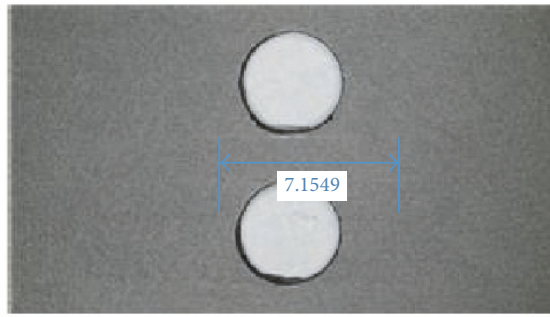

After test

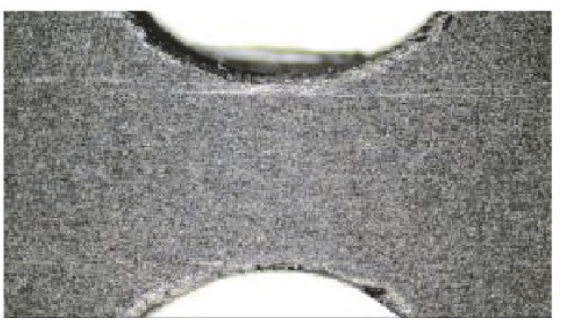

Enlarged view

Specimen 2

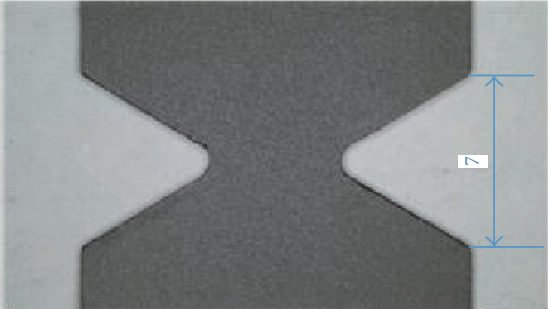

Before test

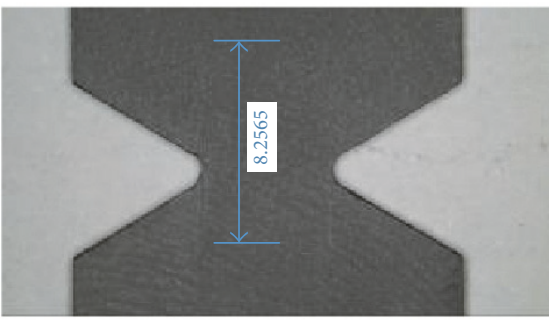

After test

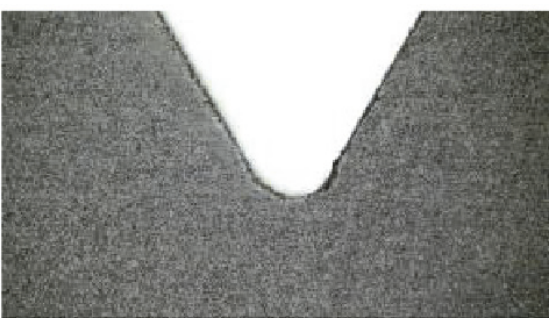

Enlarged view

Specimen 3

Figure 13: The vibration fatigue damage of different specimens.

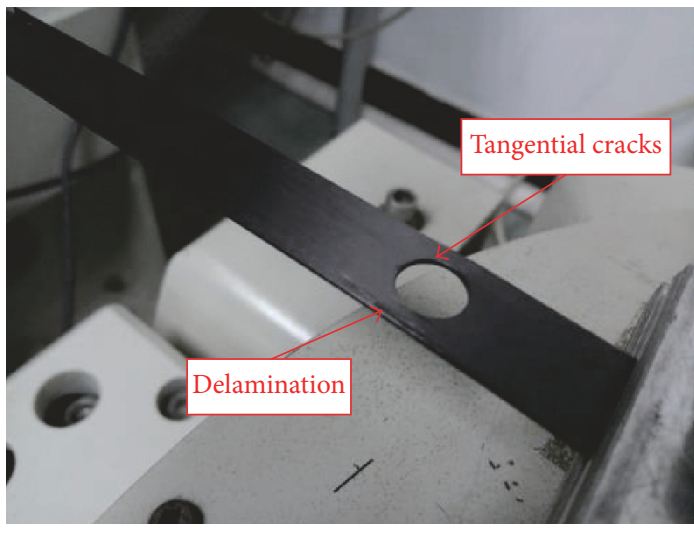

(a) Cross-ply specimen

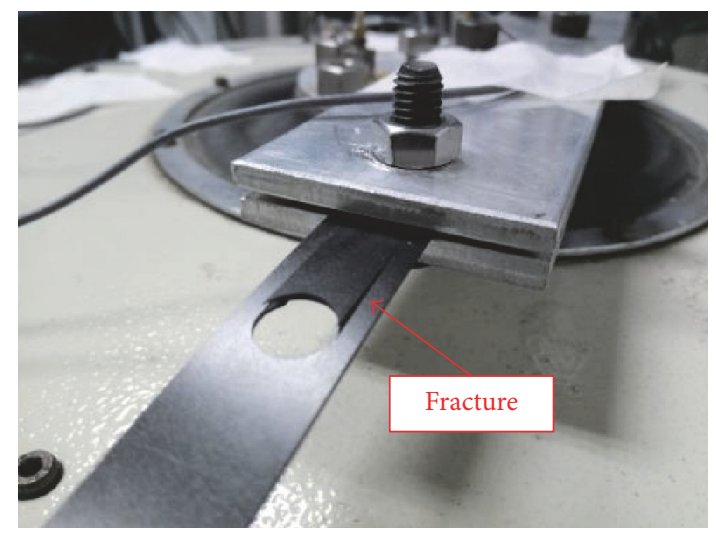

(b) Unidirectional specimen

FIGURE 14: The difference of vibration fatigue between specimens with different overlays.

drops by $0.4688 \mathrm{~Hz}$ at $101.75 \mathrm{~min}$, and the decrease rate of $\mathrm{Al}$ is the slowest. This shows that when the frequency bandwidth, PSD magnitude, and RMS value of the excitation signal are the same, the larger the kurtosis is, the more quickly the vibration fatigue damage accumulates. The test results show that the super-Gaussian random vibration load has obvious acceleration effect on the vibration fatigue of composites. As widely existing in the actual service environment of equipment, the non-Gaussian vibration load should be considered in the reliability assessment of the structure, in order to avoid a larger life expectation and catastrophic consequences.

4.4. Effects of Frequency Bandwidth on Vibration Fatigue of CFRP. The test results of Groups $\mathrm{B}$ and $\mathrm{C}$ are shown in 


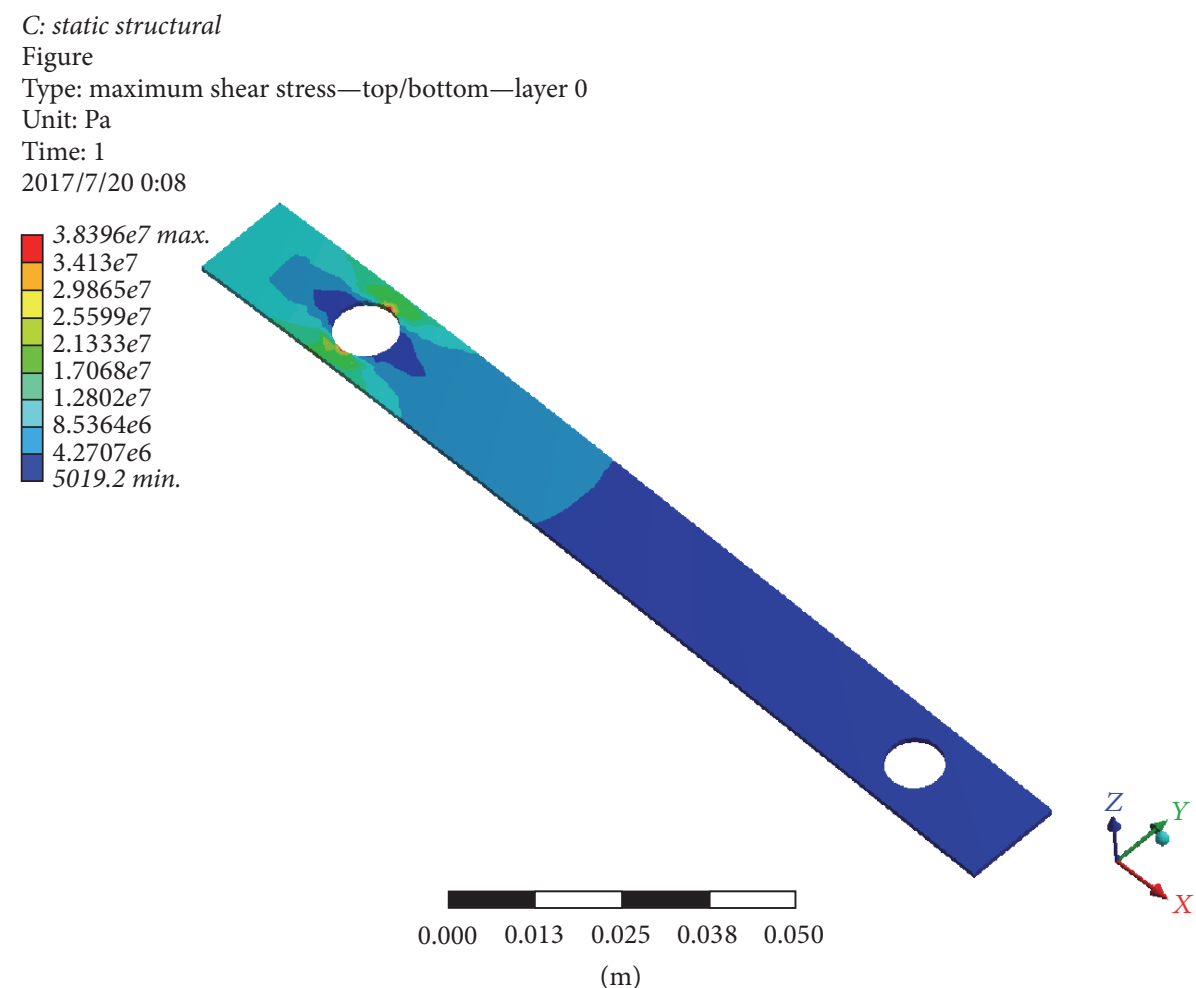

FIGURE 15: The FEA result of Specimen 1.

TABLE 5: The test results of Group A.

\begin{tabular}{lcccc}
\hline Specimen & & \multicolumn{2}{c}{ Resonant frequency } \\
Reduction $(\mathrm{Hz})$ & The time of the last decrease (min) \\
\hline A1 & 7.8906 & 7.6563 & 0.2343 & 183.25 \\
A2 & 8.1250 & 7.8125 & 0.3125 & 181.33 \\
A3 & 7.9688 & 7.5000 & 0.4688 & 101.75 \\
\hline
\end{tabular}

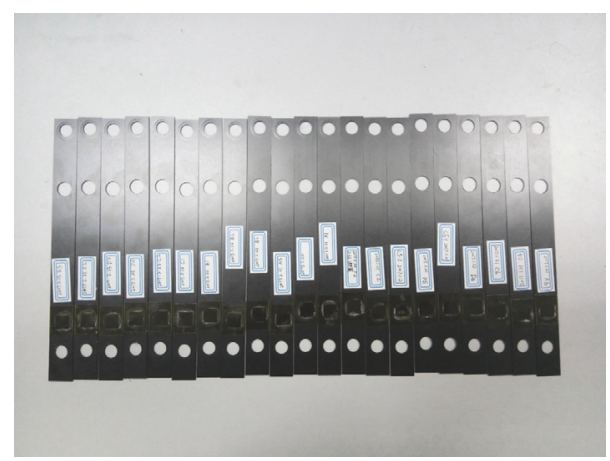

FIGURE 16: Some of the damaged test specimens.

Table 6. Figures 18 and 19 show the decreasing trend of the resonant frequency of Groups B and C.

The purpose of Group B is to explore the effect of different frequency bandwidths on the fatigue life of the composite material under the condition of Gaussian random vibration

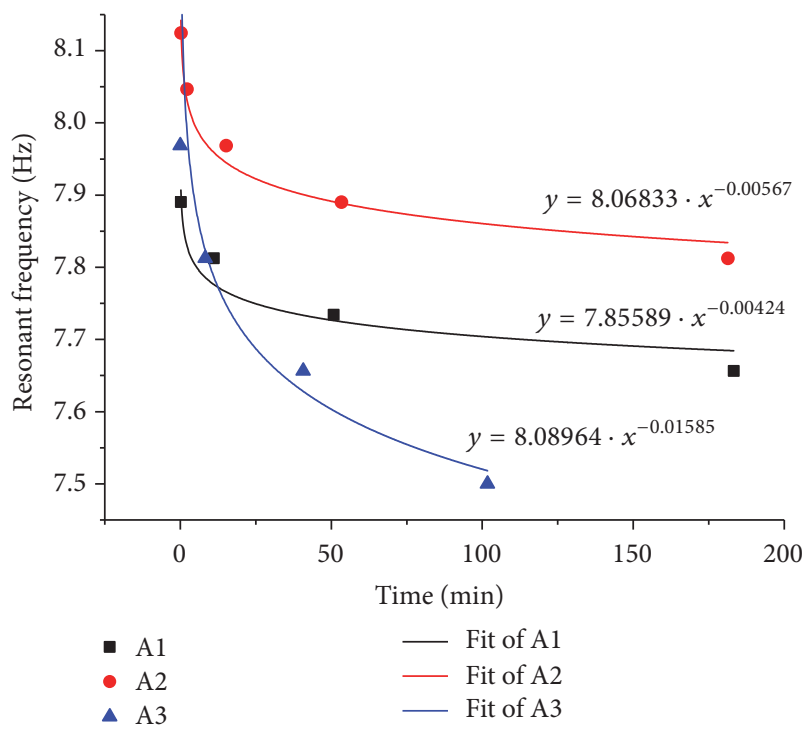

FIGURE 17: The variation and fitting curves of resonant frequency in Group A. 
TABLE 6: The test results of Group B\&C.

\begin{tabular}{lcccc}
\hline Specimen & & \multicolumn{2}{c}{ Resonant frequency } \\
Reduction $(\mathrm{Hz})$ & The time of the last decrease (min) \\
\hline B1 & 7.4158 & 7.1411 & 0.2747 & 159.33 \\
B2 & 8.1482 & 7.8735 & 0.2747 & 166.75 \\
B3 & 7.8906 & 7.6563 & 0.2343 & 183.25 \\
C1 & 7.9651 & 7.5989 & 0.3662 & 130.33 \\
C2 & 8.0566 & 7.7820 & 0.2746 & 171.83 \\
C3 & 8.0469 & 7.8125 & 0.2344 & 181.33 \\
\hline
\end{tabular}

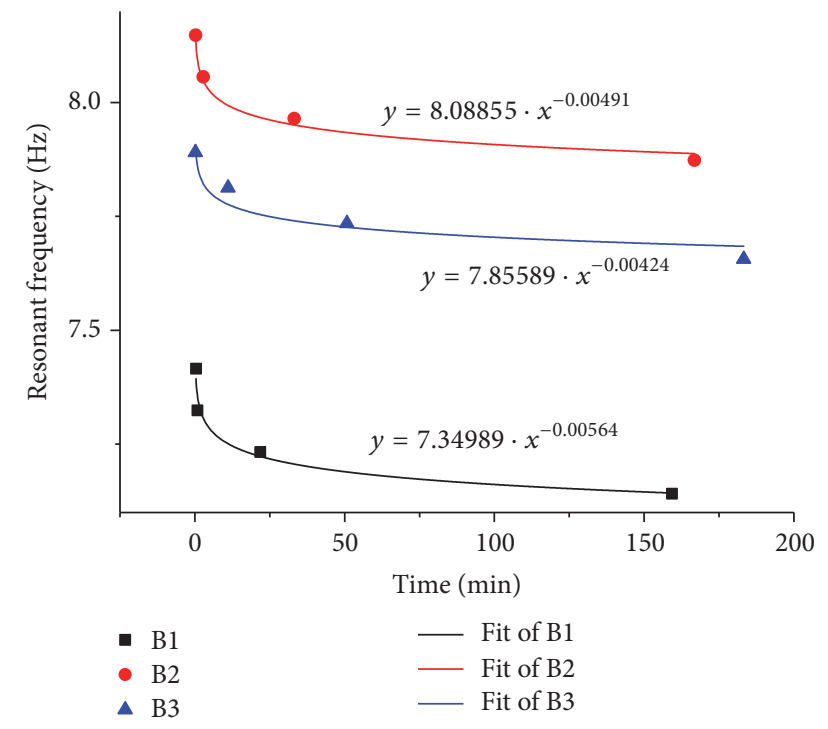

FIGURE 18: The variation and fitting curves of resonant frequency in Group B.

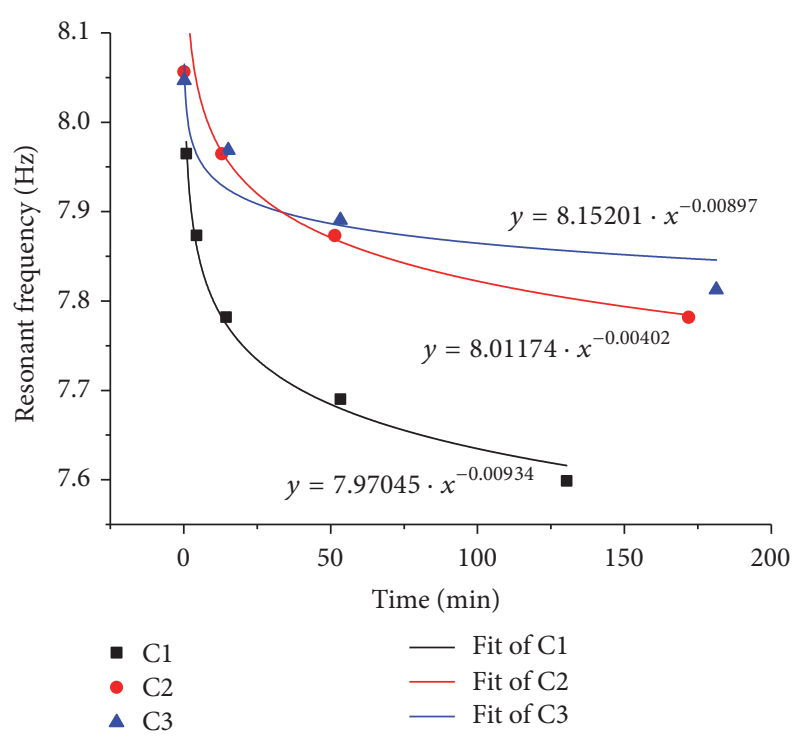

FIGURE 19: The variation and fitting curves of resonant frequency in Group C. load, and the purpose of Group C is to explore the influence of frequency bandwidth on vibration fatigue under nonGaussian random vibration load. As can be seen from Table 6 and Figures 18-19, after about the same test time, the decrease in the resonant frequency under each test condition in Group $\mathrm{B}$ is almost equal, so the decrease rate in the resonant frequency of the specimen under the three test conditions is approximately the same. This shows that, for Gaussian random vibration loads, the frequency bandwidth of the load almost has no effects on the accumulation of vibration fatigue damage of the structure. In contrast, the resonant frequency drop rate of each specimen in Group $\mathrm{C}$ is quite different. $\mathrm{C} 1$ with the lowest load frequency bandwidth has the fastest decrease rate, and its resonant frequency decreases by $0.3662 \mathrm{~Hz}$ in only $130.33 \mathrm{~min}$, while the decrease rate of C3 is the slowest. It is shown that, for the non-Gaussian random vibration load, the frequency bandwidth of the load has a significant effect on the vibration fatigue life of the material. For non-Gaussian vibration load, when the load parameters such as the magnitude of PSD and kurtosis are the same, the narrower the load frequency bandwidth, the faster the accumulation rate of vibration fatigue damage.

4.5. Effects of PSD Magnitude on Vibration Fatigue of CFRP. Table 7 shows the test results of the Groups D and E, and Figures 20-21 show the decreasing trend of the resonant frequency of the specimen. The excitation signal of Group D is Gaussian random vibration, while the excitation signal of Group $\mathrm{E}$ is super-Gaussian random vibration. From Table 7 and Figure 20, it can be seen that the time required for D3 is the least when the resonant frequency drop of the three test conditions is the same, and the time required for D1 is the longest, which indicates that the damage rate of D3 is the fastest and that of D1 is the slowest. In addition, it can be seen that the resonant frequency of E3 decreased by $0.4577 \mathrm{~Hz}$ in only $140.17 \mathrm{~min}$, while the resonant frequency of E1 decreased by only $0.2746 \mathrm{~Hz}$ in $171.83 \mathrm{~min}$, which indicates that E3 has the fastest cumulative fatigue damage rate in Group E, while E1 is the slowest. From the above test results, it can be concluded that, for the Gaussian and non-Gaussian random vibration loads, when the load frequency bandwidth and kurtosis are the same, the larger the PSD magnitude of the load signal is, the smaller the structural vibration fatigue life is. 
TABLE 7: The test result of Group D\&E.

\begin{tabular}{lcccc}
\hline Specimen & & \multicolumn{2}{c}{ Resonant frequency } \\
Reduction $(\mathrm{Hz})$ & The time of the last decrease (min) \\
\hline D1 & 8.1482 & Ultimate value $(\mathrm{Hz})$ & 0.2747 & 166.75 \\
D2 & 7.9651 & 7.6904 & 0.2747 & 150.38 \\
D3 & 7.6904 & 7.4158 & 0.2746 & 137.27 \\
E1 & 8.0566 & 7.7820 & 0.2746 & 171.83 \\
E2 & 7.5989 & 7.2327 & 0.3662 & 144.35 \\
E3 & 7.6904 & 7.2327 & 0.4577 & 140.17 \\
\hline
\end{tabular}

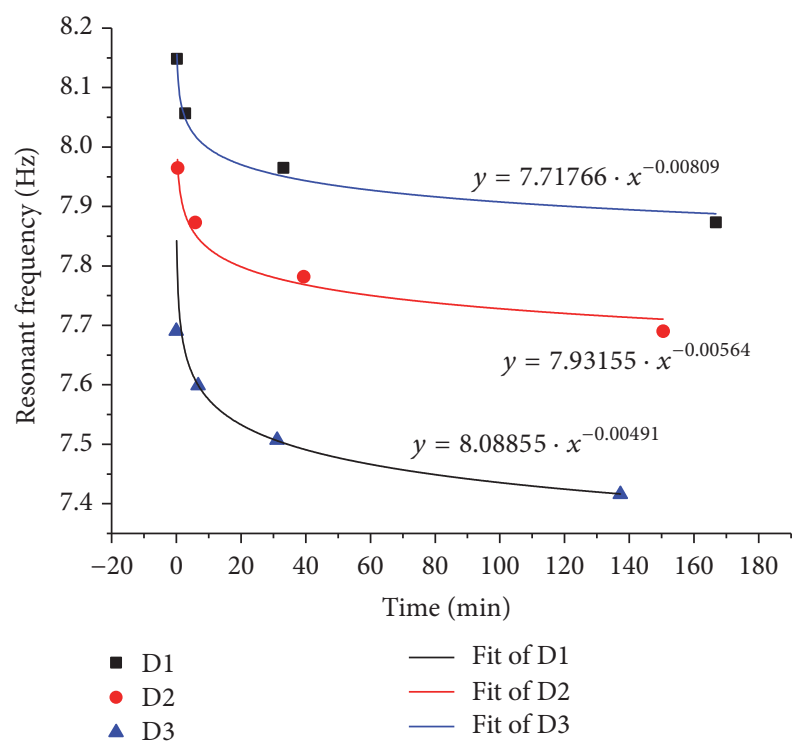

FIGURE 20: The variation and fitting curves of resonant frequency in Group D.

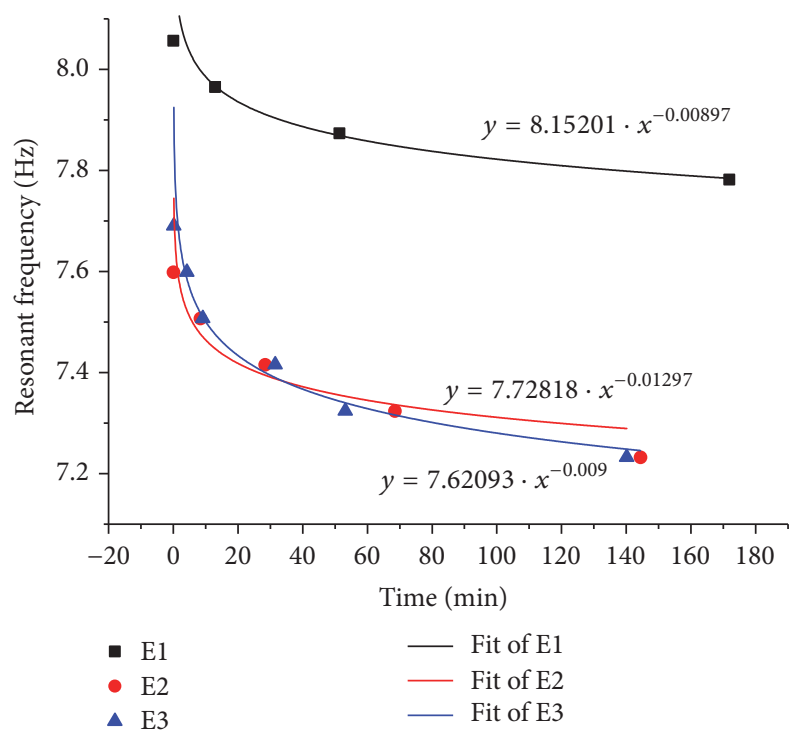

FIGURE 21: The variation and fitting curves of resonant frequency in Group E.
4.6. Effects of RMS on Vibration Fatigue of CFRP. The RMS value is affected by the frequency bandwidth and the PSD magnitude, which is not a critical factor in itself. However, the test results show that, for the non-Gaussian random vibration load, when the RMS value is larger, the structural vibration fatigue damage accumulates faster. For the Gaussian random vibration load, when the frequency bandwidth is the same, the larger the RMS value, the smaller the structural vibration fatigue life. This is mainly due to the fact that the vibration fatigue life of the composite material is mainly affected by the magnitude of the vibration at the resonant frequency.

4.7. Fitting Curve and Inverse Power Law. Figures 17-21 show the decline of the peak frequency of frequency response function (resonant frequency of the specimen) during the test. It can be seen that the fatigue damage accumulation increased as the resonant frequency decreased. The rates of the decrease were different with the different load conditions, which can reflect different influence laws of the load parameters. The fitting of the data showed that the decrease of the resonant frequency followed the inverse power-law model, and its fitting curve and function model were shown in figures. Interestingly, the classical $S-N$ curve is also a powerlaw model, as shown in (3), where $S$ is the applied stress, $N$ is the number of load cycles, and $C$ and $n$ are the parameters related to the material and structure.

$$
S=C N^{n}
$$

In addition, the fitting curve is also similar to the curve of residual stiffness in the related literature, which is about conventional fatigue of composites under constant amplitude load. This shows that the peak frequency of the frequency response function can be used as a parameter to reflect the fatigue damage accumulation. The decreasing curve in the vibration fatigue test is similar to the traditional $S-N$ curve and the residual stiffness curve. That means it can be a simple, feasible, online, real-time, and global damage index, which provides a new point of view and effective auxiliary method for the subsequent research on vibration fatigue of composite materials.

4.8. The Fatigue Threshold in the Test. There was an another interesting phenomenon in the test. No matter under any test condition, with the increase of the test time, the peak frequency of the response function declined to a certain 
degree, and then it would not decrease for a long time until the delamination damage emerged. This phenomenon was observed in all the tests in this paper, and the initial decline of resonant frequency was generally about $0.3 \mathrm{~Hz}$. It can be seen as a fatigue threshold for delamination damage.

According to the previous literature [5], there are three distinct stages during the fatigue process of FRP. The first stage is the matrix cracking, the end of which is called the characteristic damage state (CDS), where the matrix crack reaches saturation. The second stage is the cracking couplinginterfacial debonding and delamination. The last stage is near the failure phase with fiber breaking and the sudden fracture. It can be assumed that the initial decline of the peak frequency of frequency response function is actually the first fatigue stage of the specimen. When the CDS was reached, the fatigue mechanism was changed and the resonant frequency did not decrease until the delamination damage emerged. The vibration fatigue life considered in this paper is mainly in the first stage.

\section{Conclusions and Outlook}

In this paper, the fatigue life evaluation and prediction methods of FRP were summarized and reviewed firstly. It was pointed out that the fatigue of composites under complex load still needed to be deeply developed. The concept of vibration fatigue of FRP was proposed and verified through the experiment. A closed-loop controlled vibration fatigue test system suitable for CFRP and typical CFRP cantilevered laminate specimens was designed. The influence factors of vibration fatigue of CFRP were explored through the vibration testing.

The test of this paper verified that the composite material had obvious vibration fatigue phenomenon, and the damage first emerged at the risk point of structure. The vibration fatigue damage is sensitive to the notch and through-hole. In addition, the vibration fatigue damage of CFRP with different ply sequences is also different. Secondly, the effects of load parameters such as frequency bandwidth, PSD magnitude, kurtosis, and RMS on the vibration fatigue life of CFRP were investigated. For the Gaussian random vibration load, when the frequency bandwidth of the load covers the natural frequency of the structure and the other load parameters are the same, the PSD magnitude is inversely proportional to the vibration fatigue life of the composite structure, and the frequency bandwidth almost has no effect on the fatigue life. For non-Gaussian random vibration loads, when the frequency bandwidth of the load covers the natural frequency of the structure and the other load parameters are the same, the frequency bandwidth is proportional to the vibration fatigue life of the composite structure, while the PSD magnitude is inversely proportional to the vibration fatigue life. When the frequency bandwidth and kurtosis are constant, the RMS value is inversely proportional to the vibration fatigue life of the composite structure.

During the test, it is found that the decreasing trend of the resonant frequency of the structure satisfies the inverse power law, and there is an obvious fatigue threshold for delamination damage. This can provide a new point of view and effective auxiliary method for online evaluation of vibration fatigue life of composite materials.

Additionally, due to the good fatigue resistance performance (compared with metal materials) and greater dispersity of fiber-reinforced composites, it is necessary to perform long-term tests to obtain fatigue life data and to perform a large number of tests to obtain sufficient samples for a confident result, which undoubtedly makes the test cost very high and the test cycle very long. Fortunately, the accelerated life test can overcome such shortcomings. Through the accelerated test, the test cycle can be effectively compressed, and the cost is also reduced, which is particularly beneficial for the study of composite fatigue. Accelerated test can be used to evaluate the fatigue life of composite structures as an effective and reliable method. The super-Gaussian random vibration load has a significant acceleration effect on the structural vibration fatigue damage accumulation. If the acceleration effect of the super-Gaussian random vibration load can be quantitatively studied, it can be used as an effective load condition in the accelerated test.

The above research results could be used as a basis for the subsequent study on the evaluation of the fatigue life of composites under complex load. The load influence factors and their influence laws of vibration fatigue of FRP laid the foundation for the future research, which aims at the prediction and evaluation of vibration fatigue life of FRP based on accelerated testing.

\section{Conflicts of Interest}

The authors declare that there are no conflicts of interest regarding the publication of this paper.

\section{Acknowledgments}

This research was sponsored by the National Natural Science Foundation of China (Grants no. 50905181 and no. 51405501) and the National Key Laboratory Foundation of China with Grant Agreement 9140C710104140C71002. The financial support received is gratefully acknowledged. Thanks are due to Feng Zhao and Junwen Liu, who have offered great help in the experiment as laboratory technicians. Thanks are also due to Dr. Dezhi Wang, who has offered great help with the paper writing.

\section{References}

[1] P. J. C. L. Read and R. A. Shenoi, "A review of fatigue damage modelling in the context of marine FRP laminates," Marine Structures, vol. 8, no. 3, pp. 257-278, 1995.

[2] R. Sarfaraz, A. P. Vassilopoulos, and T. Keller, "A hybrid S-N formulation for fatigue life modeling of composite materials and structures," Composites Part A: Applied Science and Manufacturing, vol. 43, no. 3, pp. 445-453, 2012.

[3] D. Revuelta, J. Cuartero, A. Miravete, and R. Clemente, "New approach to fatigue analysis in composites based on residual strength degradation," Composite Structures, vol. 48, no. 1, pp. 183-186, 2000. 
[4] H. A. Whitworth, "Evaluation of the residual strength degradation in composite laminates under fatigue loading," Composite Structures, vol. 48, no. 4, pp. 261-264, 2000.

[5] J. Zong and W. Yao, "Compound model of residual stiffness degradation for FRP composites," Fuhe Cailiao Xuebao/Acta Materiae Compositae Sinica, vol. 33, no. 2, pp. 280-286, 2016.

[6] X. Tong, X. Wan, L. Yao, and Q. Sun, "Fatigue life prediction of composite material structures and components," Journal of Mechanical Strength, 1995.

[7] M. Naderi and M. M. Khonsari, "On the role of damage energy in the fatigue degradation characterization of a composite laminate," Composites Part B: Engineering, vol. 45, no. 1, pp. 528537, 2013.

[8] W. Hwang and K. S. Han, "Fatigue of Composites-Fatigue Modulus Concept and Life Prediction," Journal of Composite Materials, vol. 20, no. 2, pp. 154-165, 1986.

[9] P. Robinson, U. Galvanetto, D. Tumino, G. Bellucci, and D. Violeau, "Numerical simulation of fatigue-driven delamination using interface elements," International Journal for Numerical Methods in Engineering, vol. 63, no. 13, pp. 1824-1848, 2005.

[10] A. Turon, J. Costa, P. P. Camanho, and C. G. Dávila, "Simulation of delamination in composites under high-cycle fatigue," Composites Part A: Applied Science and Manufacturing, vol. 38, no. 11, pp. 2270-2282, 2007.

[11] B. Sun, R. Liu, and B. Gu, "Numerical simulation of threepoint bending fatigue of four-step 3-D braided rectangular composite under different stress levels from unit-cell approach," Computational Materials Science, vol. 65, pp. 239-246, 2012.

[12] E. J. Barbero, Finite Element Analysis of Composite Materials Using ANSYS, Crc Press, Baco Raton, Florida, USA, Second edition, 2013.

[13] A. P. Vassilopoulos, Fatigue life prediction of composites and composite structures, Woodhead Publishing Limited, 2010.

[14] A. P. Vassilopoulos and T. Keller, Fatigue of Fiber-reinforced Composites, Springer-Verlag, London, UK, 2011.

[15] S. Erpolat, I. A. Ashcroft, A. D. Crocombe, and M. M. AbdelWahab, "Fatigue crack growth acceleration due to intermittent overstressing in adhesively bonded CFRP joints," Composites A: Applied Science and Manufacturing, vol. 35, no. 10, pp. 1175-1183, 2004.

[16] Z. Fawaz and F. Ellyin, "Fatigue Failure Model for FibreReinforced Materials under General Loading Conditions," Journal of Composite Materials, vol. 28, no. 15, pp. 1432-1451, 1994.

[17] W. Van Paepegem and J. Degrieck, "Effects of load sequence and block loading on the fatigue response of fiber-reinforced composites," Mechanics of Advanced Materials and Structures, vol. 9, no. 1, pp. 19-35, 2002.

[18] T. P. Philippidis and A. P. Vassilopoulos, "Life prediction methodology for GFRP laminates under spectrum loading," Composites Part A: Applied Science and Manufacturing, vol. 35, no. 6, pp. 657-666, 2004.

[19] A. P. Vassilopoulos, R. Sarfaraz, B. D. Manshadi, and T. Keller, "A computational tool for the life prediction of GFRP laminates under irregular complex stress states: Influence of the fatigue failure criterion," Computational Materials Science, vol. 49, no. 3, pp. 483-491, 2010.

[20] A. Pothula, A. Gupta, and G. R. Kathawate, "Fatigue failure in random vibration and accelerated testing," Journal of Vibration and Control, vol. 18, no. 8, pp. 1199-1206, 2012.
[21] Y. Eldoǧan and E. Cigeroglu, "Vibration fatigue analysis of a cantilever beam using different fatigue theories," in Topics in Modal Analysis, Volume 7: Proceedings of the 31st IMAC, A Conference on Structural Dynamics, 2013, Conference Proceedings of the Society for Experimental Mechanics Series, pp. 471-478, Springer, New York, NY, USA, 2014.

[22] Y. Jiang, G. J. Yun, L. Zhao, and J. Tao, “Experimental design and validation of an accelerated random vibration fatigue testing methodology," Shock and Vibration, vol. 2015, Article ID 147871, 2015.

[23] M. Aykan and M. Çelik, "Vibration fatigue analysis and multiaxial effect in testing of aerospace structures," Mechanical Systems and Signal Processing, vol. 23, no. 3, pp. 897-907, 2009.

[24] S. Guanlin, H. Gengkai, and L. Bin, "Mechanics of Composite Materials," Tsinghua University Press, Springer, 2nd edition, 2013.

[25] W. J. Cantwell and J. Morton, "The impact resistance of composite materials-a review," Composites, vol. 22, no. 5, pp. 347-362, 1991.

[26] R. D. Adams, J. M. W. Brownjohn, and P. Cawley, “The detection of defects in GRP lattice structures by vibration measurements," NDT and E International, vol. 24, no. 3, pp. 123-134, 1991.

[27] R. D. Adams and P. Cawley, "Vibration techniques in nondestructive testing," 1985.

[28] R. D. Adams, D. X. Lin, and R. G. Ni, "Prediction and measurement of the natural frequencies and damping capacity of carbon fibre-reinforced plastics plates," Le Journal De Physique Colloques, vol. 44, pp. 525-530, 1983.

[29] R. D. Adams, D. Walton, J. E. Flitcroft, and D. Short, "Vibration testing as a nondestructive test tool for composite materials," Tech. Rep., Astm Special Technical Publication, 1975.

[30] J. T. Kim, Y.-S. Ryu, H.-M. Cho, and N. Stubbs, "Damage identification in beam-type structures: frequency-based method vs mode-shape-based method," Engineering Structures, vol. 25, no. 1, pp. 57-67, 2003.

[31] J. T. Kim and N. Stubbs, "Crack detection in beam-type structures using frequency data," Journal of Sound and Vibration, vol. 259, pp. 145-160, 2003.

[32] O. S. Salawu, "Detection of structural damage through changes in frequency: a review," Engineering Structures, vol. 19, no. 9, pp. 718-723, 1997.

[33] G. M. Owolabi, A. S. J. Swamidas, and R. Seshadri, "Crack detection in beams using changes in frequencies and amplitudes of frequency response functions," Journal of Sound and Vibration, vol. 265, no. 1, pp. 1-22, 2003.

[34] Y. Zou, L. Tong, and G. P. Steven, "Vibration-based modeldependent damage (delamination) identification and health monitoring for composite structures-a review," Journal of Sound and Vibration, vol. 230, no. 2, pp. 357-378, 2000.

[35] Z. Fan and Y. Jiang, "Research on vibration-based damage identification of composite materials with delamination," in The 3 rd International Conference on Structural Health Monitoring \& Integerity Management (ICSHMIM 2016), K. Ding, G. Tian, and M. Cao, Eds., Chengdu, China, 2016.

[36] L. Zhang, S. Zhang, Y. Jiang, J. Tao, and X. Chen, "Compressive behaviour of fibre reinforced plastic with random fibre packing and a region of fibre waviness," Journal of Reinforced Plastics Composites, 2016.

[37] S. Zhang, C. Zhang, and X. Chen, "Effect of statistical correlation between ply mechanical properties on reliability of fibre 
reinforced plastic composite structures," Journal of Composite Materials, vol. 49, no. 23, pp. 2935-2945, 2015.

[38] S. Zhang, L. Zhang, Y. Wang, J. Tao, and X. Chen, "Effect of ply level thickness uncertainty on reliability of laminated composite panels," Journal of Reinforced Plastics and Composites, vol. 35, no. 19, pp. 1387-1400, 2016. 


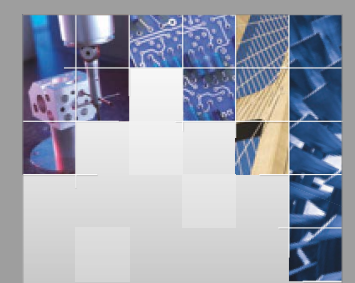

\section{Enfincering}
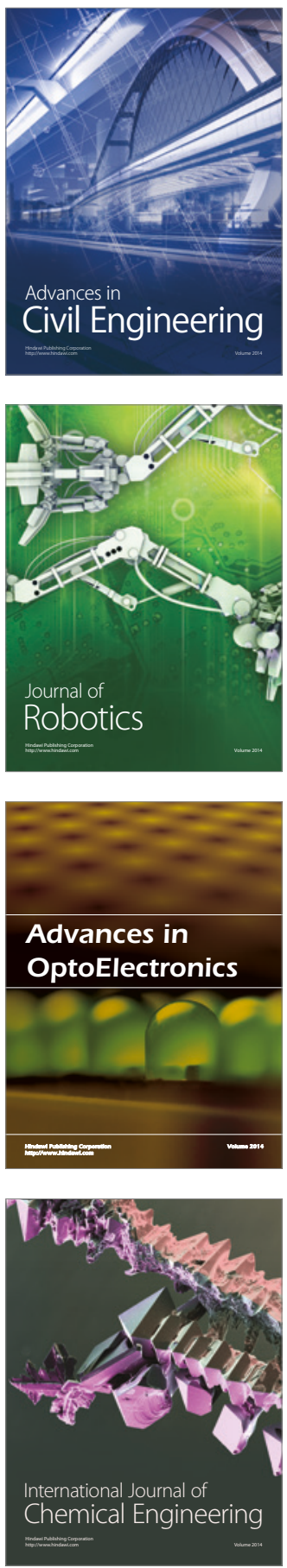

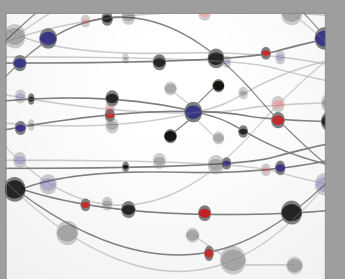

The Scientific World Journal

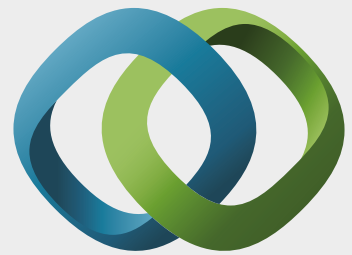

\section{Hindawi}

Submit your manuscripts at

https://www.hindawi.com
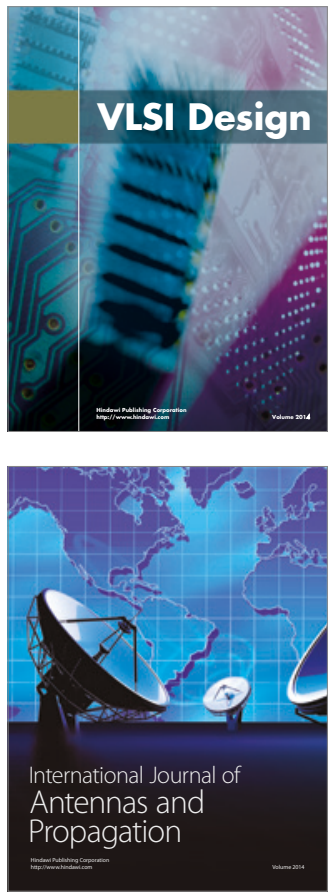

\section{Rotating}

Machinery
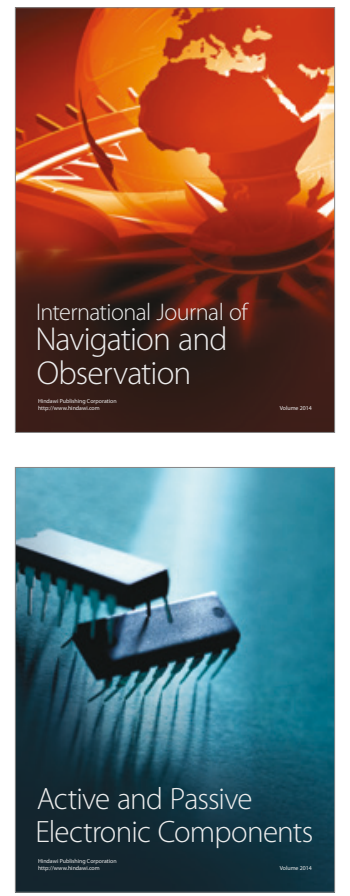
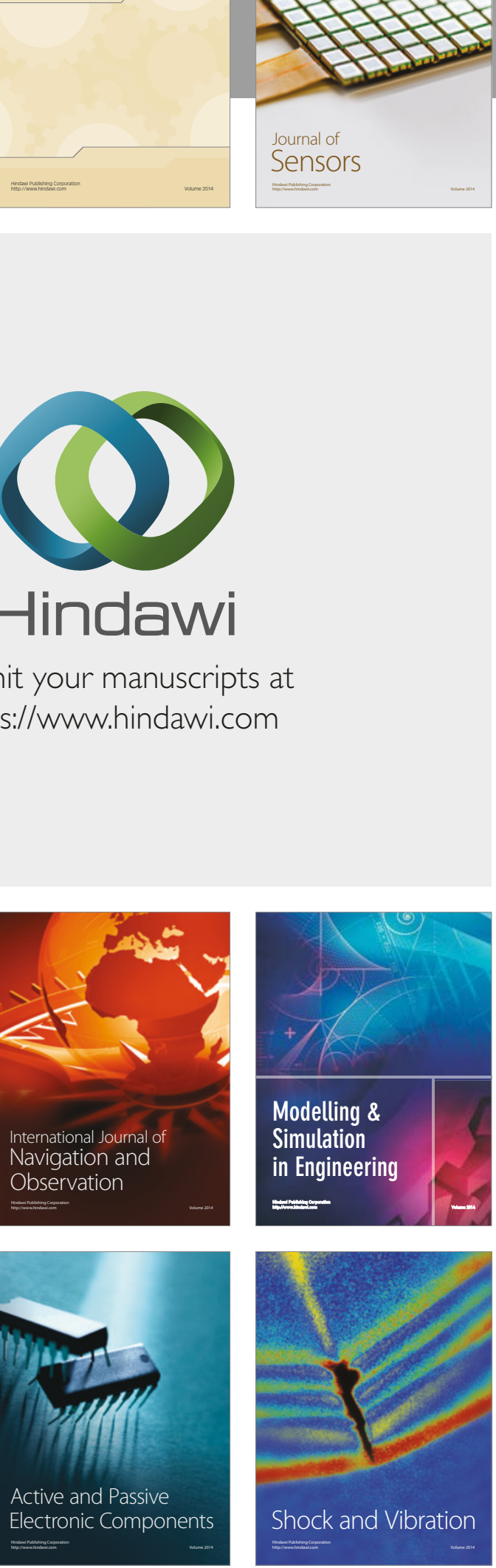
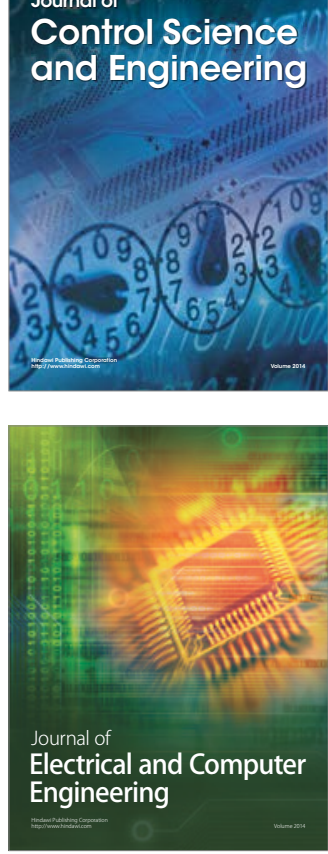

Distributed

Journal of

Control Science

and Engineering
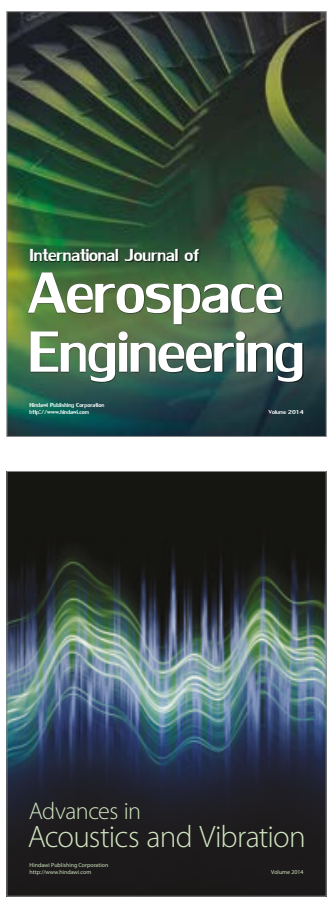

Sensor Networks 